Wright State University

CORE Scholar

$10-1-2004$

\title{
Response of the Martian Thermosphere/lonosphere to Enhanced Fluxes of Solar Soft X Rays
}

Jane L. Fox

Wright State University - Main Campus, jane.fox@wright.edu

Follow this and additional works at: https://corescholar.libraries.wright.edu/physics

Part of the Physics Commons

\section{Repository Citation}

Fox, J. L. (2004). Response of the Martian Thermosphere/lonosphere to Enhanced Fluxes of Solar Soft X Rays. Journal of Geophysical Research-Space Physics, 109, A11310.

https://corescholar.libraries.wright.edu/physics/23

This Article is brought to you for free and open access by the Physics at CORE Scholar. It has been accepted for inclusion in Physics Faculty Publications by an authorized administrator of CORE Scholar. For more information, please contact library-corescholar@wright.edu. 


\title{
Response of the Martian thermosphere/ionosphere to enhanced fluxes of solar soft $X$ rays
}

\author{
J. L. Fox \\ Department of Physics, Wright State University, Dayton, Ohio, USA \\ Received 7 January 2004; revised 18 August 2004; accepted 3 September 2004; published 18 November 2004.
}

[1] We have investigated the response of the thermosphere and ionosphere of Mars to enhanced fluxes of solar soft $\mathrm{X}$ rays, such as those that have been detected by the SNOE satellite (e.g., Bailey et al., 2000). We have constructed standard models by adopting the SC\#21REFW and F79050N solar fluxes from H. E. Hinteregger (private communication) (see also Torr et al., 1979) for the low and high solar activity models, respectively. We then constructed enhanced soft X-ray models by multiplying the solar photon fluxes for wavelengths below $200 \AA$ by a factor of 3 at low solar activity and by a factor of 6 at high solar activity. We discuss the effects of the larger fluxes of soft X rays on the ion and electron density profiles and the minor neutral density profiles. We find that increasing the Hinteregger soft X-ray fluxes by a uniform factor below $200 \AA$ cannot reproduce the distinct lower peaks that have been observed in some of the electron density profiles measured by the radio science experiment on the Mars Global Surveyor (MGS), and that were modeled previously by Fox et al. (1995) using the SERF2 solar fluxes of Tobiska (1991). In our model computations, the lower peak appears only as a shoulder, although the magnitude of the electron density at the shoulder is comparable to those exhibited by the MGS radio occultation profiles. This is in contrast to models of the terrestrial ionosphere, where increasing the solar fluxes by a uniform factor of 2-4 for wavelengths less than $250 \AA$ has been found to bring the model electron and NO density profiles, and the shape of the photoelectron flux spectra, into agreement with the measured values. INDEX TERMS: 5435 Planetology: Solid Surface Planets: Ionospheres (2459); 0343 Atmospheric Composition and Structure: Planetary atmospheres (5405, 5407, 5409, 5704, 5705, 5707); 2459

Ionosphere: Planetary ionospheres $(5435,5729,6026,6027,6028)$; 5704 Planetology: Fluid Planets:

Atmospheres - composition and chemistry; KEYWORDS: Mars thermosphere, Mars ionosphere, soft X rays

Citation: Fox, J. L. (2004), Response of the Martian thermosphere/ionosphere to enhanced fluxes of solar soft X rays, J. Geophys. Res., 109, A11310, doi:10.1029/2004JA010380.

\section{Introduction}

[2] That the solar soft X-ray fluxes were underestimated by the standard solar flux models of $\mathrm{H}$. E. Hinteregger (private communication, 1980) [see also Torr et al., 1979] has been suggested by several measurements and models. Richards and Torr [1984] modeled the photoelectron fluxes derived from the Atmospheric Explorer-E (AE-E) satellite [Lee et al., 1980] at solar minimum and found that the shape of the suprathermal photoelectron flux spectra could be reproduced by doubling the solar fluxes of the Hinteregger F74113 spectrum below $250 \AA$. This was considered justifiable because the F74113 fluxes shortward of $250 \AA$ were not measured on day 113 of 1974, but were derived from other measurements [Heroux and Hinteregger, 1978]. Both the F74113 and SC\#21REF solar fluxes pertain to low solar activity conditions. Richards et al. [1994] proposed that the F74113 spectrum, which was based on measurements from a rocket flight [Heroux and Higgens, 1977],

Copyright 2004 by the American Geophysical Union. 0148-0227/04/2004JA010380 better reflected low solar activity conditions than the SC\#21REF spectrum, which was obtained from extrapolation of AE-E measurements from 1977 and 1980, a time of relatively high solar activity. The SC\#21REF spectrum was normalized by utilizing solar flux data from a 1979 rocket flight [Hinteregger et al., 1981]. The F74113 fluxes are about a factor of 2 larger than the SC\#21REF fluxes below $300 \AA$. Richards et al. proposed that the fluxes of the SC\#21REF spectrum for wavelengths less than $300 \AA$ should be increased by up to a factor of 4 to reproduce the shape of the AE-E model photoelectron spectra.

[3] Conway [1984] modeled the AE-E dayglow spectrum in the $3300-3500 \AA$ region. He found that by including the the $(0,9)$ Vegard-Kaplan (VK) band at $3200 \AA$ along with the $(0,0) \mathrm{N}_{2}$ second positive band at $3371 \AA$, the dayglow intensities measured by the AE-E filter photometer could be brought into agreement with the photoelectron theory of Kopp et al. [1977]. An analysis of the predicted and measured second positive dayglow intensities, however, indicated that the photoelectron fluxes measured by AE-E were too large by a factor of nearly two. Undoubtedly many parameters used in these older models have been updated. 
Strickland et al. [1999] later showed by using their Atmospheric Ultraviolet Radiance Integrated Code (AURIC) that better agreement with the measured photoelectron fluxes could be obtained by increasing the Hinteregger solar fluxes for photons with wavelengths below $250 \AA$ by a factor of 2 .

[4] Ogawa and Judge [1986] used a rocket-borne $\mathrm{Ne}$ ionization chamber to measure the integrated solar flux between 50 and $575 \AA$, with an estimated error of $7.3 \%$. Their results indicated that the Hinteregger fluxes in this wavelength region were low by a factor of 2 at low solar activity and by $30 \%$ at high solar activity. Because the wavelength range of the measurements extended well into the EUV, the amount of the underestimate due to soft $\mathrm{X}$ rays could not be determined.

[5] Barth et al. [1988; see also Barth, 1996] proposed that since the highly variable solar fluxes with wavelengths from 20 to $100 \AA$ deposit their energy in the terrestrial altitude region where the NO densities are observed to maximize, the energetic photoelectrons produced by these soft $\mathrm{X}$ rays were responsible for the large magnitudes and variability in the low latitude NO densities observed by the Solar Mesophere Explorer (SME) satellite. The SME ultraviolet spectrometer measured the NO densities through observations of the $(1,0)$ NO $\gamma\left(A^{2} \Sigma^{+} \rightarrow X^{2} \Pi\right)$ band at $2150 \AA$ as a function of altitude and latitude over the period 1982 to 1986 . The maximum densities at low latitudes were observed near $110 \mathrm{~km}$. The large densities at high latitudes are assumed to be produced by auroral energetic $(\sim 1-$ $10 \mathrm{keV}$ ) electron precipitation [e.g., Gérard and Barth, 1977; Gérard et al., 1984; Barth et al., 2003; Petrinec et al., 2003]. Cleary [1986] developed a photochemical model of the NO densities in which variations in the EUV fluxes did not reproduce the observed low latitude NO density variations. The NO densities did, however, respond to larger variations in the soft $\mathrm{X}$ rays. Indeed, unit optical depth for wavelengths between 250 and $1000 \AA$ in the terrestrial atmosphere is reached between 150 and $170 \mathrm{~km}$, whereas soft $\mathrm{X}$ rays with wavelengths less than $150 \AA$ are absorbed below $120 \mathrm{~km}$, near the maximum of the nitric oxide density profile.

[6] The Student Nitric Oxide Explorer (SNOE) Solar Xray Photometer (SXP) was designed to determine the soft $\mathrm{X}$-ray fluxes using a series of photodiodes with thin film coatings rather than the less reliable foil filters [e.g., Bailey et al., 1999a]. The measurements were reported as daily averages of X-ray fluxes in three channels $(20-70 \AA$, $60-$ $190 \AA$, and 170-200 А) beginning in March 1998 [e.g., Bailey et al., 2000]. The NO density profiles were obtained from limb scans of the fluorescent scattered emission from the $(1,0)$ and $(0,1) \gamma$ bands by the ultraviolet spectrometer. Barth et al. [1999] found a correlation between the magnitude of the soft X-ray fluxes and the densities of equatorial $\mathrm{NO}$ as returned by the first four months of SNOE data in mid-1998. For the period of the measurements, which was at moderate solar activity, they found that the Hinteregger models underpredicted the magnitude of the soft X-ray fluxes in all three channels. Bailey et al. [2000] reported the fluxes in the three wavelength channels for a range of $F_{10.7}$ from about 100 to 175 , and showed that the photon fluxes increased over this range by factors of $8.3,7.0$, and 3.5 for the $20-70,60-190$, and $170-200 \AA$ channels, respectively. Solomon et al. [2001] showed that increasing the Hinteregger solar fluxes for moderate solar activity by a factor of 4 for wavelengths less than $250 \AA$ brought their model profiles of the terrestrial electron density into agreement with the incoherent scatter profiles of Buonsanto et al. [1992, 1995]. The SNOE data showed also that the longterm variability in the solar soft $\mathrm{X}$ rays was larger than the Hinteregger solar spectra predicted [Bailey et al., 2000].

[7] In the past, various investigators have identified different wavelength ranges as that for which the fluxes were underestimated in the Hinteregger spectra. Upper wavelength limits between 100 and $300 \AA$ have been assumed [e.g., Barth et al., 1988; Richards et al., 1994; Strickland et al., 1999; Bailey et al., 1999b; Solomon et al., 2001]. Solomon et al. [2001] described the wavelength range 10-300 $\AA$ as the "XUV" or hard extreme ultraviolet to soft X-ray region. In their ionosphere model, they increased the solar fluxes below $250 \AA$ by a uniform factor of 4 . We find that, if the solar photon fluxes with wavelengths up to $250-300 \AA$ are increased, significant increases of the main $F_{1}$ peaks of both the Earth and Mars will be produced.

[8] Electron density profiles in the Martian ionosphere were returned from the radio science (RS) experiment on board the Mars Global Surveyor [e.g., Tyler et al., 2001] (D. P. Hinson and the MGS Radio Science Team, Public access to MGS RS standard electron density profiles, available at http://nova.stanford.edu/projects/mgs/eds-public.html, 2003). A survey of these profiles shows the existence of a prominent $E$-region below the main $F_{1}$ peak. This feature sometimes appears as a shoulder and sometimes as a separate peak. We note here that the definition of the $E$ and $F_{1}$ regions and peaks that we have adopted is based on the differences in the sources of the ions, and is the same as that used by Bauer [1973] and Banks and Kockarts [1977]. The $F_{1}$ peak is defined as arising from ionization by photons in the main part of the solar EUV spectrum, from about 250 to $910 \AA$. The $E$ region is formed by ionization by soft $\mathrm{X}$ rays characterized by wavelengths less than 150 , and by UV photons with wavelengths longer than $910 \AA$. On Earth, the latter source is more important than on Mars or Venus because $\mathrm{O}_{2}$, which is a major constituent in the terrestrial thermosphere, is ionized by solar Lyman $\beta$ at $1026 \AA . \mathrm{O}_{2}$ is only a minor constituent in the thermospheres of both Mars and Venus.

[9] The SERF2 solar spectra of Tobiska [1991] were characterized by a larger ratio of soft $\mathrm{X}$ ray to EUV photon fluxes than the Hinteregger (SERF1) fluxes [cf. Buonsanto et al., 1992]. Fox et al. [1995] used the SERF2 fluxes to model the Martian thermosphere/ionosphere. These models (hereafter the SERF2 models) were the first models that showed a distinct lower peak in the Martian electron density profile. The SERF2 electron density profiles are shown in Figure 1, where they are compared to the Mariner 6 ingress radio occultation electron density profile [Fjeldbo et al., 1970]. Only a shoulder appeared in models that were based on the Hinteregger solar fluxes. The magnitudes of the lower peaks in the Mariner 6 radio occultation electron density profiles were between those computed with the SERF2 solar fluxes and those computed with the Hinteregger solar fluxes.

[10] We have constructed updated standard and enhanced soft X-ray models for both low and high solar activities. 


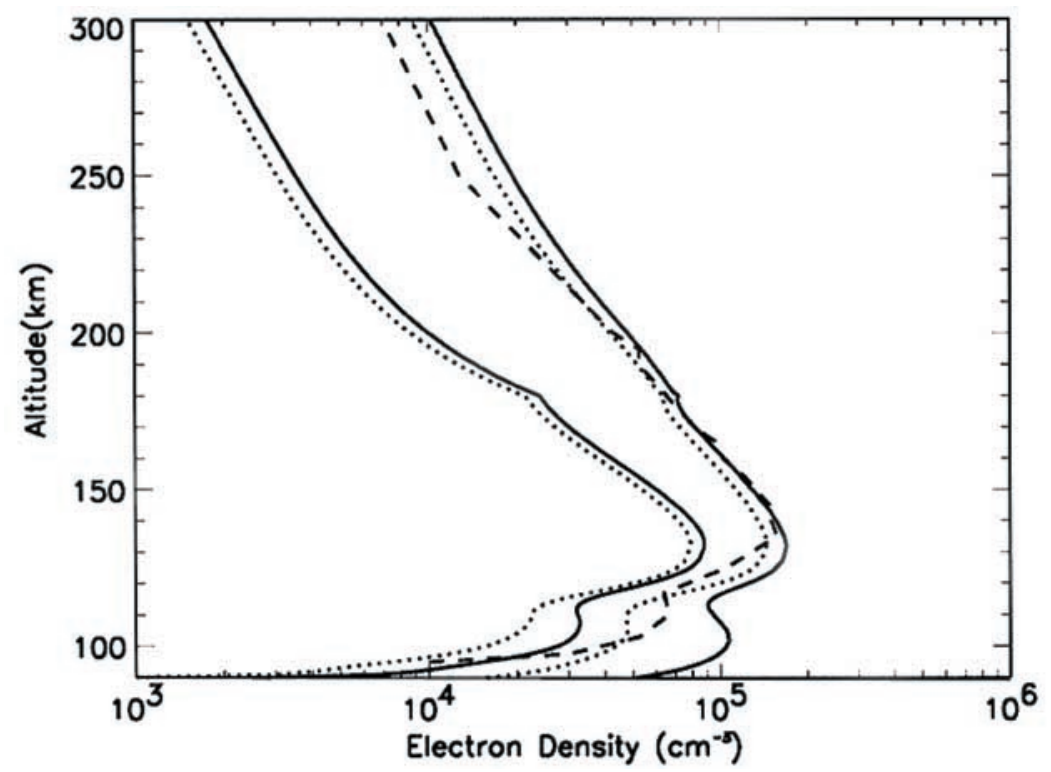

Figure 1. Electron density profiles for the low and high solar activity Hinteregger and SERF2 models. The larger densities are from the high solar activity models, and the smaller densities are from the low solar activity models. The solid curves are those from the SERF2 models, and the dotted curves were computed using the Hinteregger SC21REFW and F79050N spectra for low and high solar activities, respectively. The dashed curve is a smoothed electron density profile derived from the Mariner 6 radio occultation profiles [Fjeldbo et al., 1970]. Taken from Fox et al. [1995].

For the solar fluxes in the wavelength range from 18 to $2000 \AA$, we have adopted the SC\#21REFW and F79050N spectra from H. E. Hinteregger (private communication) [see also Torr et al., 1979; Hinteregger et al., 1981] for the low and high solar activity standard models, respectively. In the version we use, the photon fluxes are given as delta functions at the strong solar lines and at $1 \mathrm{~A}$ intervals in the continuum from 18.62 to $2000 \AA$. We also include hard $\mathrm{X}$ rays in our model. The solar fluxes in the region $\lambda$ $<20 \AA$ are greatly affected by solar flares, these fluxes are known to be quite variable [e.g., Banks and Kockarts, 1977]. For the wavelength range $1-17 \AA$ in the high solar activity standard model we have adopted the photon fluxes at $1 \AA$ intervals that were obtained from Ayres [1997, also private communication, 1996], and we reduced those fluxes by a factor of 50 for low solar activity. The Yohkoh Soft X-ray Telescope (SXT) returned relative X-ray emissions for the wavelength range 3-37 $\AA$; these data showed a variability of a factor of about 100 from low to high solar activity [Acton et al., 1999]. In order to mimic this variation, for the high solar activity enhanced X-ray model we have increased the hard X-ray solar fluxes by a factor of 2. For the low solar activity enhanced X-ray model, we used the same 1-17 $\AA$ fluxes as the standard model. The variability of the fluxes in this wavelength region is so large that the adopted fluxes should only be considered as estimates. Furthermore, these photons are absorbed below $100 \mathrm{~km}$ in the D-region, which is below the region of interest here. We have assumed a solar zenith angle of $60^{\circ}$ in all the models presented here, and an average heliocentric distance for Mars of 1.523 AU.

[11] The SNOE data suggested that the Hinteregger soft X-ray fluxes were underpredicted more at high than at low solar activity [Bailey et al., 2000]. For the enhanced soft
X-ray models, (hereafter the enhanced X-ray models) the solar photon fluxes for wavelengths in the range 18 to $200 \AA$ in our models were increased by factors of 3 and 6 at low and high solar activities, respectively. Bougher et al. [2001] increased the soft X-ray fluxes below $150 \AA$ by a factor of 10 in their Mars Thermospheric General Circulation Model (MTGCM) to produce a lower peak in the electron density profiles that could be compared to those observed by the MGS. We investigate here the response of the thermosphere and ionosphere of Mars to enhanced fluxes of solar soft X rays, including ion production rates, ion and electron density profiles, and density profiles of the minor species $\mathrm{NO}, \mathrm{N}\left({ }^{4} S\right), \mathrm{N}\left({ }^{2} D\right), \mathrm{N}\left({ }^{2} P\right)$, and $\mathrm{C}$.

\section{Background Models}

[12] The background models have been updated since 1995 and contain 12 species, as shown in Figure 2. Only $\mathrm{H}_{2}$ has been added to the background atmosphere since 1995. As Fox [2001, 2003a] has shown, however, $\mathrm{H}_{2}$ in abundances greater than 4 ppm has a significant effect on the $\mathrm{O}^{+}, \mathrm{CO}^{+}$, $\mathrm{CO}_{2}^{+}$, and $\mathrm{N}_{2}^{+}$density profiles. The low solar activity model used here is based on the measurements of Viking [e.g., Nier and McElroy, 1976], and the high solar activity model is based on density profiles taken from the MTGCM of Bougher et al. [1990, 1999, 2000, also private communication, 2000]. The exospheric temperatures in the low and high solar activity models are $200 \mathrm{~K}$ and $300 \mathrm{~K}$, respectively. The mixing ratio of $\mathrm{O}$ in the low solar activity model is 0.02 at $130 \mathrm{~km}$, and was derived from the Viking Retarding Potential Analyzer (RPA) measurements of the $\mathrm{O}_{2}^{+}$and $\mathrm{CO}_{2}^{+}$profiles by Fox and Dalgarno [1979]. Values between 0.01 and 0.03 have been derived by other investigators [e.g., Nier et al., 1976; Hanson et al., 1977; Krasnopolsky, 2002]. At high 

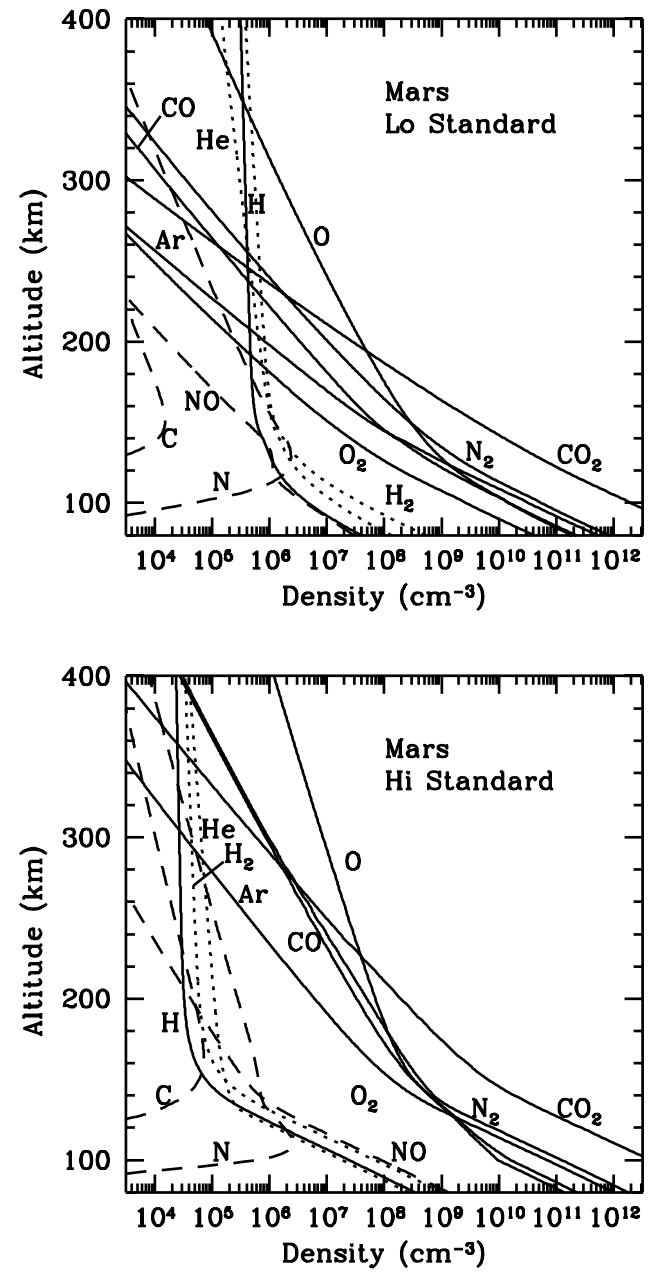

Figure 2. Background neutral density profiles for standard low and high solar activity models. The molecular and $\mathrm{H}$ density profiles are represented by solid curves; He and $\mathrm{H}_{2}$ densities are represented by dotted curves; $\mathrm{C}, \mathrm{N}$, and NO density profiles are represented by dashed curves. The latter densities are computed self-consistently in the models, and the variations in these densities from the standard to enhanced X-ray models are presented in Figure 11 below. The $\mathrm{H}$ and $\mathrm{H}_{2}$ density profiles also vary for the enhanced $\mathrm{X}$-ray models, but these variations are not discussed here. (top) Standard low solar activity model ("Lo"). (bottom) Standard high solar activity model ("Hi").

solar activity, the $\mathrm{O}$ density profile was taken from the MTGCM, and its abundance is approximately 0.017 at $130 \mathrm{~km}$. Since $\mathrm{O}$ is produced by photolysis of $\mathrm{CO}_{2}$, we might expect that, by analogy to Venus, the $\mathrm{O}$ abundances would be larger at high solar activity. It is possible that dynamical processes, including large scale winds and eddy diffusion, act to limit the mixing ratio variations over a solar cycle [e.g., Bougher et al., 2000]. In addition, there is a lack of data on the $\mathrm{O}$ abundances at both low and high solar activities. We therefore chose not to change the $\mathrm{O}$ density profile in the MTGCM model. The resulting O mixing ratios at the $F_{1}$ peaks are similar for all the models, ranging from 0.027 to 0.029 near $136 \mathrm{~km}$ at low solar activity and from 0.025 to 0.027 near $138 \mathrm{~km}$ at high solar activity.
[13] We adopted an $\mathrm{H}_{2}$ abundance at the lower boundary of 15 ppm, as derived by Krasnopolsky and Feldman [2001] from intensities of $(6,3)$ and $(6,1)$ bands of the $\mathrm{H}_{2}$ Lyman $\left(B^{1} \Sigma_{u}^{+} \rightarrow X^{1} \Sigma_{g}^{+}\right)$band system, which they measured using the Far Ultraviolet Spectrometer Explorer (FUSE). The atomic hydrogen densities at the lower boundary were fixed so that the densities at $250 \mathrm{~km}$ were similar to those inferred from the models of Krasnopolsky and Feldman [2001], about $4 \times 10^{5} \mathrm{~cm}^{-3}$ at low solar activity and $3 \times 10^{4} \mathrm{~cm}^{-3}$ at high solar activity. The high solar activity value is consistent with that determined from analyses of the Lyman alpha emissions measured on the Mariner spacecraft [e.g., Anderson and Hord, 1971]. At the tops of the models, we imposed upward velocity boundary conditions on $\mathrm{H}$ and $\mathrm{H}_{2}$. The upward velocities of $\mathrm{H}$ were reduced by a factor of 2 from the theoretical Jeans velocities, to account for suppression of the tail of the velocity distribution by the escaping atoms, as suggested by Shizgal and Blackmore [1986]. A helium abundance of 4 ppm [Krasnopolsky and Gladstone, 1996] was imposed at the lower boundaries of the models. The N, NO, and C profiles were computed selfconsistently in the models.

[14] The set of photoabsorption and photoionization cross sections that we have adopted has undergone considerable revision since the 1995 SERF2 models were published. Among other changes, some of which were reported by Fox and Sung [2001], we have adopted the short wavelength cross sections from the calculations of Verner and Yakovlev [1995] for atoms. For molecules, the k-shell cross sections were assumed to be the sum of those for the constituent atoms. We adopted the theoretical cross sections from $1 \AA$ to the shortest wavelength for which measured cross sections were available for each species. The photoabsorption cross sections for $\mathrm{O}$ in particular have been thoroughly revised since 1995, as described by Fox and Sung [2001].

[15] The photoelectron grid extends from 0 to $300 \mathrm{eV}$, in $1 \mathrm{eV}$ intervals. Electrons produced with energies greater than $300 \mathrm{eV}$ by the absorption of $\mathrm{X}$ rays, and auger electrons from $\mathrm{k}$-shell ionization of $\mathrm{O}$ and $\mathrm{C}$ are included approximately, however, by dividing the energy of the electron in $\mathrm{eV}$ by 300 , placing the appropriate number of electrons into the top energy bin, and by placing one electron into the bin which represents the remainder of the energy. Thus the energy of the all the photoelectrons is accounted for, but the primary electron production spectra have anomalous peaks, particularly at $300 \mathrm{eV}$.

[16] The full set of chemical reactions and rate coefficients in the Venus/Mars model was reported by Fox and Sung [2001]. Modifications to the rate coefficients since that compilation include that for the reaction

$$
\mathrm{NO}+\mathrm{N} \rightarrow \mathrm{N}_{2}+\mathrm{O} .
$$

The 2003 JPL evaluation recommends the value $2.1 \times$ $10^{-11} \exp (100 / T) \mathrm{cm}^{3} \mathrm{~s}^{-1}$ [DeMore et al., 1994; Sander et al., 2003], rather than the constant value of $3.4 \times 10^{-11}$ $\mathrm{cm}^{3} \mathrm{~s}^{-1}$ recommended previously [Lee et al., 1978; DeMore et al., 1992]. The recommended values do not apply to the temperatures below $200 \mathrm{~K}$, such as those in the Martian lower thermosphere. The measurements of Wennberg et al. [1994] indicate a slight negative temperature dependence down to temperatures of $220 \mathrm{~K}$, but they 
Table 1. Revised Transition Probabilities ${ }^{\mathrm{a}}$

\begin{tabular}{llll}
\hline Wavelength, $\AA$ & \multicolumn{1}{c}{ Transition, } & \multicolumn{1}{c}{$\mathrm{A}, \mathrm{s}^{-1}$} & \multicolumn{1}{c}{ Reference $^{\mathrm{a}}$} \\
\hline 3728,3726 & $\mathrm{O}^{+}\left({ }^{2} D\right) \rightarrow \mathrm{O}^{+}\left({ }^{4} S\right)+h \nu$ & $8.88 \times 10^{-5}$ & Zeippen [1982] \\
7319,7329 & $\mathrm{O}^{+}\left({ }^{2} P\right) \rightarrow \mathrm{O}^{+}\left({ }^{2} D\right)+h \nu$ & $1.733 \times 10^{-1}$ & Zeippen [1982] \\
2470 & $\mathrm{O}^{+}\left({ }^{2} P\right) \rightarrow \mathrm{O}^{+}\left({ }^{4} S\right)+h \nu$ & $4.53 \times 10^{-2}$ & Zeippen [1982] \\
5200 & $\left.\mathrm{~N}^{2} D\right) \rightarrow \mathrm{N}\left({ }^{4} S\right)+h \nu$ & $1.28 \times 10^{-5}$ & Butler and Zeippen [1984] \\
10,400 & $\mathrm{~N}\left({ }^{2} P\right) \rightarrow \mathrm{N}\left({ }^{2} D\right)+h \nu$ & $8.0 \times 10^{-2}$ & Butler and Zeippen [1984] \\
3466 & $\mathrm{~N}\left({ }^{2} P\right) \rightarrow \mathrm{N}\left({ }^{4} S\right)+h \nu$ & $5.308 \times 10^{-3}$ & Butler and Zeippen [1984] \\
6300,6364 & $\left.\mathrm{O}\left({ }^{1} D\right) \rightarrow \mathrm{O}{ }^{3} P\right)+h \nu$ & $7.445 \times 10^{-3}$ & Baluja and Zeippen [1988] \\
5577 & $\mathrm{O}\left({ }^{1} S\right) \rightarrow \mathrm{O}\left({ }^{1} D\right)+h \nu$ & 1.215 & Baluja and Zeippen [1988] \\
2972 & $\mathrm{O}\left({ }^{1} S\right) \rightarrow \mathrm{O}\left({ }^{3} P\right)+h \nu$ & $7.601 \times 10^{-2}$ & Baluja and Zeippen [1988] \\
\hline
\end{tabular}

${ }^{\mathrm{a}}$ As collected by Swaminathan et al. [1998].

suggest that their measurements do not rule out some nonArrhenius behavior. Subsequent calculations of the rate coefficient for this radical-radical reaction [e.g., Duff and Sharma, 1997; Gamallo et al., 2003], however, support the measurements.

[17] The branching ratios of the products of $\mathrm{O}_{2}^{+}$dissociative recombination

$$
\mathrm{O}_{2}^{+}+\mathrm{e} \rightarrow \mathrm{O}+\mathrm{O}
$$

for the first two channels reported in Fox and Sung [2001] contain a slight error. The branching ratios for the channels that produce $\mathrm{O}\left({ }^{3} P\right)+\mathrm{O}\left({ }^{3} P\right)$ and $\mathrm{O}\left({ }^{3} P\right)+\mathrm{O}\left({ }^{1} D\right)$ were given as 0.20 and 0.44 , respectively, whereas those measured by Kella et al. [1997] were actually 0.22 and 0.42 , respectively. Peverall et al. [2001] more recently measured the branching ratios as a function of energy from $1 \mathrm{meV}$ to $3 \mathrm{eV}$. They found the branching ratios to be highly energy-dependent, especially the yield of $\mathrm{O}\left({ }^{1} S\right)$ at thermal energies, which they found to be in the range 0.011 to 0.019 . The Kella et al. [1997] $\mathrm{O}\left({ }^{1} S\right)$ yield was reported as 0.05 for dissociative recombination of ground state $\mathrm{O}_{2}^{+}$and 0.09 for a vibrationally excited sample of $\mathrm{O}_{2}^{+}$. Because $\mathrm{O}_{2}^{+}$is vibrationally excited at high altitudes [e.g., Fox and Hać, 1997], and because of uncertainties in the electron temperatures and the subsequent difficulties in applying the branching ratios of Peverall et al. [2001], we have chosen to retain the branching ratios of Kella et al. [1997].

[18] The transition probabilities (Einstein A-factors) for the most important forbidden transitions of metastable excited states of $\mathrm{O}^{+}, \mathrm{O}$, and $\mathrm{N}$ given by Fox and Sung [2001] have been superseded by the later calculations of Zeippen [1982], Butler and Zeippen [1984], and Baluja and Zeippen [1988], as pointed out by Swaminathan et al. [1998]. The more recent values are listed in Table 1.

[19] The ion density profiles were computed with zeroflux upper boundary conditions, and consequently the high altitude ion scale heights and densities are overestimated. Several investigators have shown that the major ion densities measured by the RPA on Viking [Hanson et al., 1977] can only be reproduced in 1-D models by imposing upward velocity boundary conditions at the tops of the models [e.g., Chen et al., 1978; Shinagawa and Cravens, 1989; Fox, 1993, 1997]. This upward flux represents a high altitude loss process for the ions, probably the divergence of the horizontal fluxes. Fox [1997] showed that the loss rates of ions are limited roughly by their production rates above the photochemical equilibrium region, and predicted that the ion with the largest loss rate would be $\mathrm{O}_{2}^{+}$. Ma et al. [2002; see also Liu et al., 2001] used multi-species MHD models of the ionosphere/solar wind interaction to show that ions are indeed transported at high altitudes across the terminator. The trans-terminator ion fluxes computed by $M a$ et al. are within the upper limits reported by Fox [1997], and the escape rates are roughly in agreement with values derived from the ASPERA instrument on the Phobos mission [e.g., Lundin et al., 1989]. Most of the analyses of Phobos data, however, were based on the assumption that the major escaping ion was $\mathrm{O}^{+}$[e.g., Lundin et al., 1990; Verigin et al., 1991; Kallio et al., 1995; Lichtenegger and Dubinin, 1998; Jin et al., 2001]. Ma et al. [2004] recently computed trans-terminator and escape fluxes of $\mathrm{O}^{+}, \mathrm{O}_{2}^{+}$, and $\mathrm{CO}_{2}^{+}$for a new MHD model on a spherical grid with finer altitude resolution. The results of the calculations for several cases showed significantly smaller fluxes. We focus here, however, on the major $F_{1}$ and lower $E$-region peak electron densities, which are not expected to be affected by the upper boundary condition. All the high altitude ion densities reported here are expected to be too large, as are density peaks for ions that maximize at high altitudes, including $\mathrm{O}^{+}, \mathrm{H}^{+}, \mathrm{He}^{+}, \mathrm{N}_{2}^{+}$, and $\mathrm{CO}^{+}$.

\section{Photoionization Rates}

[20] The solar photoproduction rates of $\mathrm{CO}_{2}^{+}, \mathrm{N}_{2}^{+}, \mathrm{CO}^{+}$, $\mathrm{NO}^{+}, \mathrm{O}^{+}, \mathrm{C}^{+}$, and $\mathrm{N}^{+}$are shown in Figures 3 and 4 , for the low and high solar activity models, respectively. In the figures we present both the production rates for models computed with the standard Hinteregger solar fluxes, and those for the enhanced X-ray fluxes, which were described previously. In Table 2, we present summaries of the altitudes and magnitudes of the peaks of the photoionization rate profiles for seven ions. The main peaks in the production profiles are due mostly to absorption of the portion of the EUV from 250 to $910 \AA$. The major ion produced is $\mathrm{CO}_{2}^{+}$, and its production rate maximizes at $\sim 136 \mathrm{~km}$ at low solar activity and $\sim 139 \mathrm{~km}$ at high solar activity. When the soft X-ray fluxes are enhanced, the peak photoionization rates are located $\sim 0.5-1 \mathrm{~km}$ lower in the ionosphere, and the peak photoproduction rate of $\mathrm{CO}_{2}^{+}$increases by $5 \%$ at low solar activity, and by $14 \%$ at high solar activity.

[21] Most of the production profiles also exhibit lower shoulders in the ranges $106-109$ and $112-115 \mathrm{~km}$, for low and high solar activity models, respectively, which result from the absorption of soft $\mathrm{X}$ rays. When only a lower shoulder appears, the altitude of the lower peak is identified as that for which the difference between the production rates at successive altitudes is a minimum; thus the altitude of the shoulder usually is placed between two integer altitudes, 


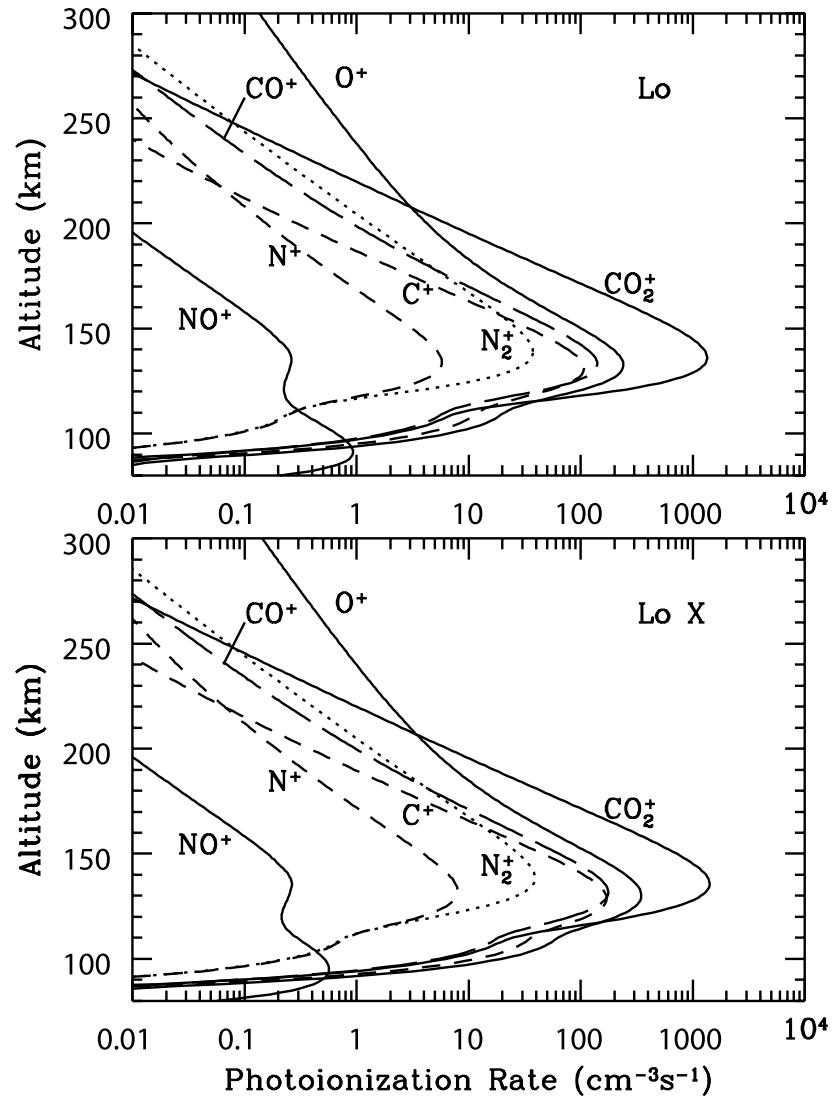

Figure 3. Altitude profiles of the production rates of seven ions by photoionization for the low solar activity models. (top) Standard model ("Lo"). (bottom) Enhanced X-ray model ("Lo X").

and is somewhat uncertain because of the $1 \mathrm{~km}$ altitude grid size. This method was also used to locate the shoulders in the profiles for the electron-impact ionization rates and the steady state model ion densities. For example, when the soft $\mathrm{X}$ rays are enhanced, the $\mathrm{CO}_{2}^{+}$production rate profile exhibits a lower shoulder near $106.5 \mathrm{~km}$ with a magnitude that increases by a factor of $\sim 3$ at low solar activity; the shoulder appears near $112.5 \mathrm{~km}$ and increases by a factor of $\sim 6$ at high solar activity. These factors are essentially the same as those by which the soft $\mathrm{X}$ rays have been increased. That the photoionization rates near the main peak increase shows that photons with wavelengths below $200 \AA$ are absorbed in this region as well.

[22] The photoproduction rate of ions is dominated by that of $\mathrm{CO}_{2}^{+}$from $\sim 115$ to $207 \mathrm{~km}$ and from $\sim 116$ to $244 \mathrm{~km}$ at low and high solar activities, respectively; at higher altitudes production of $\mathrm{O}^{+}$is more important. $\mathrm{O}$ becomes the dominant neutral above 195 and $225 \mathrm{~km}$ in our low and high solar activity models, respectively. The difference between the "cross-over" altitudes for the neutral densities and the ion production rates reflects the difference in the photoionization cross sections, which are larger for $\mathrm{CO}_{2}$ than for $\mathrm{O} . \mathrm{CO}_{2}$ and $\mathrm{O}$ have similar ionization thresholds: $13.76 \mathrm{eV}$ for $\mathrm{CO}_{2}$ and 13.6 for $\mathrm{O}$. Near the main peak in the $\mathrm{O}^{+}$photoproduction rate, which occurs in the range $133-$ $135 \mathrm{~km}$ in the standard model, and $130-131 \mathrm{~km}$ in the enhanced X-ray model, the most important production process is photodissociative ionization of $\mathrm{CO}_{2}$; at higher altitudes direct ionization of $\mathrm{O}$ dominates. Thus the photoionization rate profile above the peak follows the density profile of $\mathrm{CO}_{2}$ at lower altitudes and that of $\mathrm{O}$ at higher altitudes. The calculated production rate of $\mathrm{O}^{+}$from dissociative ionization of $\mathrm{CO}_{2}$ exceeds production of $\mathrm{CO}_{2}^{+}$ below $\sim 116 \mathrm{~km}$ at low solar activity and below $\sim 122 \mathrm{~km}$ at high solar activity.

[23] Figures 3 and 4 and Table 2 show that the photoionization rate profiles of $\mathrm{NO}^{+}$peak near $91 \mathrm{~km}$ at low solar activity, and near $95 \mathrm{~km}$ at high solar activity. Most of the photoionization near the peak is produced by the absorption of solar Lyman alpha photons near $1216 \AA$. The magnitudes of the production rates at these altitudes decrease slightly as the solar soft $\mathrm{X}$ rays are enhanced for both low and high solar activities. This reflects the small decrease in NO densities in this altitude range in the enhanced X-ray models. Although the larger fluxes of soft $\mathrm{X}$ rays increase the odd nitrogen densities in this altitude range as they do on the Earth, the increase on Mars is reflected in larger densities of atomic $\mathrm{N}$ rather than NO. As will be shown below, our model does not reproduce the Viking measured NO densities [e.g., Nier et al., 1976] in the 120-140 km region [cf. Fox, 1993, 1994]. There also is a secondary peak in the photoproduction rate of $\mathrm{NO}^{+}$near $135 \mathrm{~km}$ at low solar activity and a prominent shoulder at high solar activity near $139-142 \mathrm{~km}$. These features arise from photoionization of NO by solar

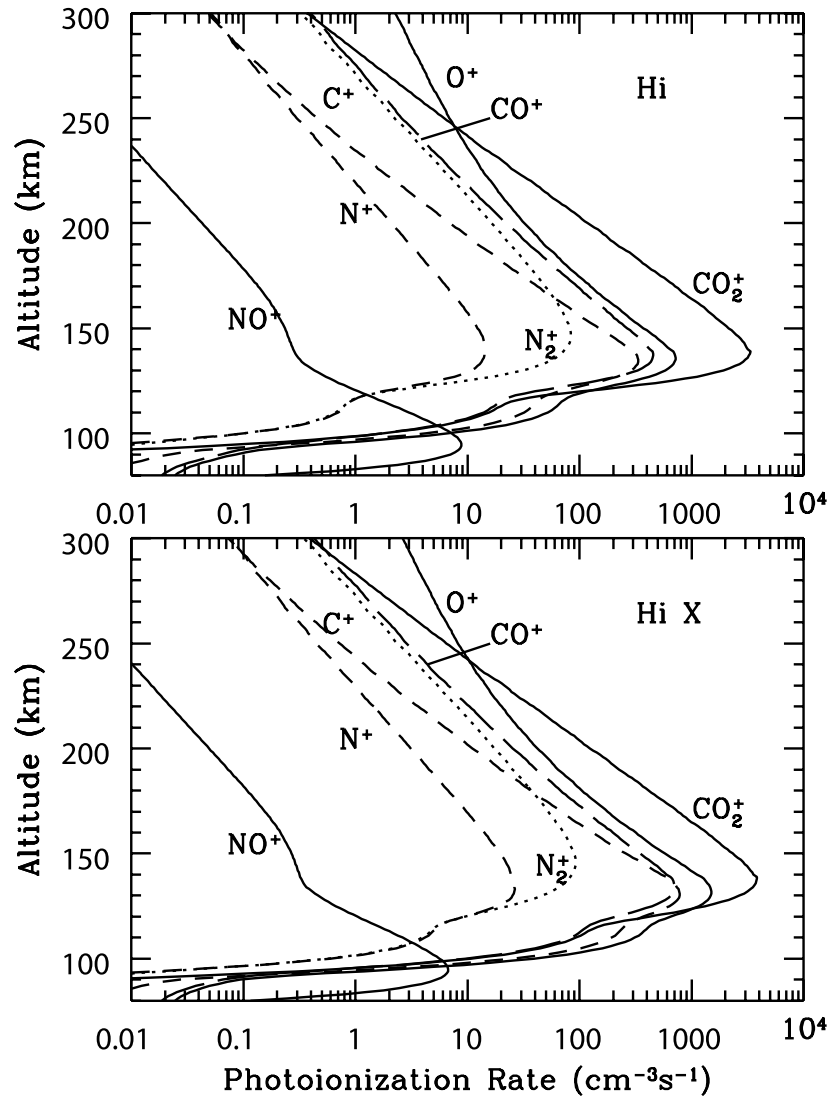

Figure 4. Altitude profiles of the production rates of seven ions by photoionization for the high solar activity models. (top) Standard model ("Hi"). (bottom) Enhanced X-ray model ("Hi X"). 
Table 2. Peak Altitudes and Production Rates Due to Photoionization for the Low and High Solar Activity Standard and Enhanced X-Ray Models

\begin{tabular}{|c|c|c|c|c|c|}
\hline Species & $\begin{array}{c}\text { Altitude, } \\
\text { km }\end{array}$ & $\begin{array}{l}\text { Production } \\
\text { Rate, } \\
\mathrm{cm}^{-3} \mathrm{~s}^{-1}\end{array}$ & $\begin{array}{c}\text { Altitude, } \\
\text { km }\end{array}$ & $\begin{array}{l}\text { Production } \\
\text { Rate, } \\
\mathrm{cm}^{-3} \mathrm{~s}^{-1}\end{array}$ & Ratio $^{a}$ \\
\hline \multicolumn{6}{|c|}{ Low Standard and Enhanced X-Ray Models } \\
\hline \multirow{2}{*}{$\mathrm{CO}_{2}^{+}$} & 136 & $1.35(3)^{\mathrm{b}}$ & 135.5 & $1.42(3)$ & 1.05 \\
\hline & 116.5 & $5.6(0)$ & 106.5 & $1.7(1)$ & 3.0 \\
\hline \multirow[t]{2}{*}{$\mathrm{N}_{2}^{+}$} & 139 & $3.7(1)$ & 138.5 & $3.9(1)$ & 1.05 \\
\hline & 108.5 & $2.3(-1)$ & 108.5 & $6.9(-1)$ & 3.0 \\
\hline \multirow[t]{2}{*}{$\mathrm{O}^{+}$} & 132 & $2.4(2)$ & 130.0 & $3.5(2)$ & 1.44 \\
\hline & 108.5 & $1.8(1)$ & 108.5 & $5.5(1)$ & 3.0 \\
\hline \multirow[t]{2}{*}{$\mathrm{CO}^{+}$} & 133.5 & $1.40(2)$ & 131.5 & $1.76(2)$ & 1.26 \\
\hline & 108.5 & $5.4(0)$ & 108.5 & $1.63(1)$ & 3.0 \\
\hline \multirow[t]{2}{*}{$\mathrm{C}^{+}$} & 131.5 & $1.07(2)$ & 128.5 & $1.70(2)$ & 1.6 \\
\hline & 108.5 & $1.04(1)$ & 108.5 & $3.1(1)$ & 3.0 \\
\hline \multirow[t]{2}{*}{$\mathrm{N}^{+}$} & 134 & $5.8(0)$ & 132 & $8.0(0)$ & 1.4 \\
\hline & 108.5 & $2.4(-1)$ & 108.5 & $7.2(-1)$ & 3.0 \\
\hline \multirow[t]{2}{*}{$\mathrm{NO}^{+}$} & 135 & $2.6(-1)$ & 132 & $2.6(-1)$ & 0.9 \\
\hline & 91.5 & $9.3(-1)$ & 91.5 & $7.9(-1)$ & 0.9 \\
\hline \multicolumn{6}{|c|}{ High Standard and Enhanced X-Ray Models } \\
\hline \multirow[t]{2}{*}{$\mathrm{CO}_{2}^{+}$} & 139 & $3.3(3)$ & 139 & $3.8(3)$ & 1.14 \\
\hline & 112.5 & $1.92(1)$ & 112.5 & $1.15(2)$ & 6.0 \\
\hline \multirow[t]{2}{*}{$\mathrm{N}_{2}^{+}$} & 146.5 & $8.4(1)$ & 146 & $9.3(1)$ & 1.10 \\
\hline & 113.5 & $8.0(-1)$ & 113.5 & $4.8(1)$ & 6.0 \\
\hline \multirow[t]{2}{*}{$\mathrm{O}^{+}$} & 135.5 & $7.2(2)$ & 132 & $1.50(2)$ & 2.1 \\
\hline & 113.5 & $5.7(1)$ & 113.5 & $3.4(2)$ & 6.0 \\
\hline \multirow[t]{2}{*}{$\mathrm{CO}^{+}$} & 137 & $4.5(2)$ & 134 & $7.1(2)$ & 1.6 \\
\hline & 113.5 & $1.7(1)$ & 113.5 & $1.01(2)$ & 6.0 \\
\hline \multirow[t]{2}{*}{$\mathrm{C}^{+}$} & 135 & $3.3(2)$ & 131 & $7.8(2)$ & 2.4 \\
\hline & 114.5 & $3.4(1)$ & 114.5 & $2.0(2)$ & 6.0 \\
\hline \multirow[t]{2}{*}{$\mathrm{N}^{+}$} & 137.5 & $1.4(1)$ & 132 & $2.6(1)$ & 1.85 \\
\hline & 114.5 & $2.7(0)$ & 114.5 & $1.6(1)$ & 6.0 \\
\hline \multirow[t]{2}{*}{$\mathrm{NO}^{+}$} & 139.5 & $2.8(-1)$ & 138.5 & $3.3(-1)$ & 1.16 \\
\hline & 95 & $8.8(0)$ & 95 & $7.0(0)$ & 0.8 \\
\hline
\end{tabular}

${ }^{a}$ Ratio of peak production rates for the enhanced X-ray model to those of the standard model.

EUV photons. Ambient $\mathrm{NO}^{+}$is, however, produced mostly in chemical reactions, and the direct ionization of NO has little effect on the density profiles of $\mathrm{NO}^{+}$.

[24] Figures 3 and 4 also show the photoproduction rates as a function of altitude for $\mathrm{CO}^{+}, \mathrm{C}^{+}, \mathrm{N}_{2}^{+}$, and $\mathrm{N}^{+}$. The photoproduction rate profiles of all these species exhibit a main peak and a lower shoulder. For the enhanced soft $\mathrm{X}$-ray models we compute slightly larger production rates at the main peak and significantly larger production rates near the lower shoulders. For example, when the solar soft X-ray spectrum is enhanced, the main peaks in the computed photoionization profiles of $\mathrm{CO}_{2}^{+}$and $\mathrm{N}_{2}^{+}$increase by only small factors of 1.05-1.06 at low solar activity, and by factors of 1.12-1.17 at high solar activity. These increases are relatively small because the only source for each of these ions is photoionization of the parent neutrals, and most of the photoproduction of $\mathrm{CO}_{2}^{+}$and $\mathrm{N}_{2}^{+}$is due to absorption of photons with wavelengths between $250 \AA$ and the thresholds at 901 and $796 \AA$, respectively.

[25] The increases in the production rates when the soft $\mathrm{X}$ rays are enhanced are larger for ions with multiple sources, such as $\mathrm{CO}^{+}, \mathrm{O}^{+}, \mathrm{C}^{+}$, and $\mathrm{N}^{+}$; the factors by which the peak photoionization rate increases are in the range 1.3-2.0. This can be understood because these ions are produced mainly by photodissociative ionization of $\mathrm{CO}_{2}$ and $\mathrm{N}_{2}$ near and below the main peak. The threshold wavelengths for photodissociative ionization of $\mathrm{CO}_{2}$ to produce $\mathrm{CO}^{+}, \mathrm{C}^{+}$, and $\mathrm{O}^{+}$, are 637,404 , and $651 \AA$, respectively. The threshold for production of $\mathrm{N}^{+}$from photodissociative ionization of $\mathrm{N}_{2}$ is $510 \AA$. Thus the photoproduction rates of these fragment ions are more sensitive to increases in the short wavelength region of the spectrum. By contrast, the threshold wavelengths for direct photoionization of $\mathrm{CO}, \mathrm{O}, \mathrm{C}$ and $\mathrm{N}$ are longer: $885,911,1101$, and $853 \AA$, respectively. The production rates of $\mathrm{CO}^{+}, \mathrm{O}^{+}, \mathrm{N}^{+}$, and $\mathrm{C}^{+}$by direct photoionization of the parent neutrals are very small near the peaks of the production profiles. Direct ionization of the parent neutrals is, however, important at high altitudes.

[26] As Table 2 shows, the factors by which the lower shoulders in all the production profiles increase are virtually the same as the factors by which the solar soft X-ray fluxes are assumed to increase. At low solar activity, the lower peaks in the photoproduction rate profiles of $\mathrm{CO}_{2}^{+}, \mathrm{N}_{2}^{+}, \mathrm{O}^{+}$, $\mathrm{C}^{+}$, and $\mathrm{N}^{+}$increase by factors of $\sim 3.0$ from the standard to the enhanced X-ray models; at high solar activity, the lower peaks in the production rates of these ions increase by factors of $\sim 6.0$. This clearly demonstrates that the lower peaks in the photoionization profiles are produced by photons with wavelengths less than 200, although this does not constrain the upper wavelength limit of the enhanced solar fluxes, which may in fact be less than $200 \AA$.

\section{Electron-Impact Production Rates}

[27] The model electron-impact ionization production rates are shown as a function of altitude for $\mathrm{CO}_{2}^{+}, \mathrm{O}^{+}$, $\mathrm{CO}^{+}, \mathrm{N}_{2}^{+}, \mathrm{C}^{+}, \mathrm{N}^{+}$and $\mathrm{NO}^{+}$for the low and high solar activity models in Figures 5 and 6, respectively. The top panels show the production rates computed with the standard solar fluxes, and the bottom panels show those computed with enhanced $\mathrm{X}$ rays. The altitudes and magnitudes of the peak production rates by electron-impact are summarized in Table 3. We have found that EUV photons with wavelengths shorter than $200 \AA$ penetrate to altitudes below 128 to $133 \mathrm{~km}$ in our $60^{\circ} \mathrm{SZA}$ models.

[28] The production of energetic photoelectrons is mostly controlled by photoionization of $\mathrm{CO}_{2}$. Therefore the lower shoulders in the production rates of all the ions by electronimpact increase by nearly the same factors as those by which the soft $\mathrm{X}$ rays are assumed to be enhanced, that is, factors of 3 and 6 for low and high solar activities, respectively, at altitudes of $110-112 \mathrm{~km}$ and $113-115 \mathrm{~km}$, respectively. The main part of the EUV is absorbed near $136 \mathrm{~km}$ at low solar activity and near $139 \mathrm{~km}$ at high solar activity. The electronimpact production rates peak $6-8 \mathrm{~km}$ lower than the photoproduction peaks for both standard models. In the enhanced X-ray models, the peaks for electron-impact ionization are $9-17 \mathrm{~km}$ below those for photoionization. The altitude of peak production by electron impact is lower than that by photoionization because, in general, the higher energy soft X-ray photons penetrate further into the atmosphere. As is well known, absorption of soft $\mathrm{X}$ rays, unlike the major portion of the EUV, produces higher energy photoelectrons, double ionization of valence shell electrons, and k-shell (or inner shell) ionization. K-shell ionization can lead to the ejection of a very energetic auger electron in the subsequent reorganization of the atom. These high energy 


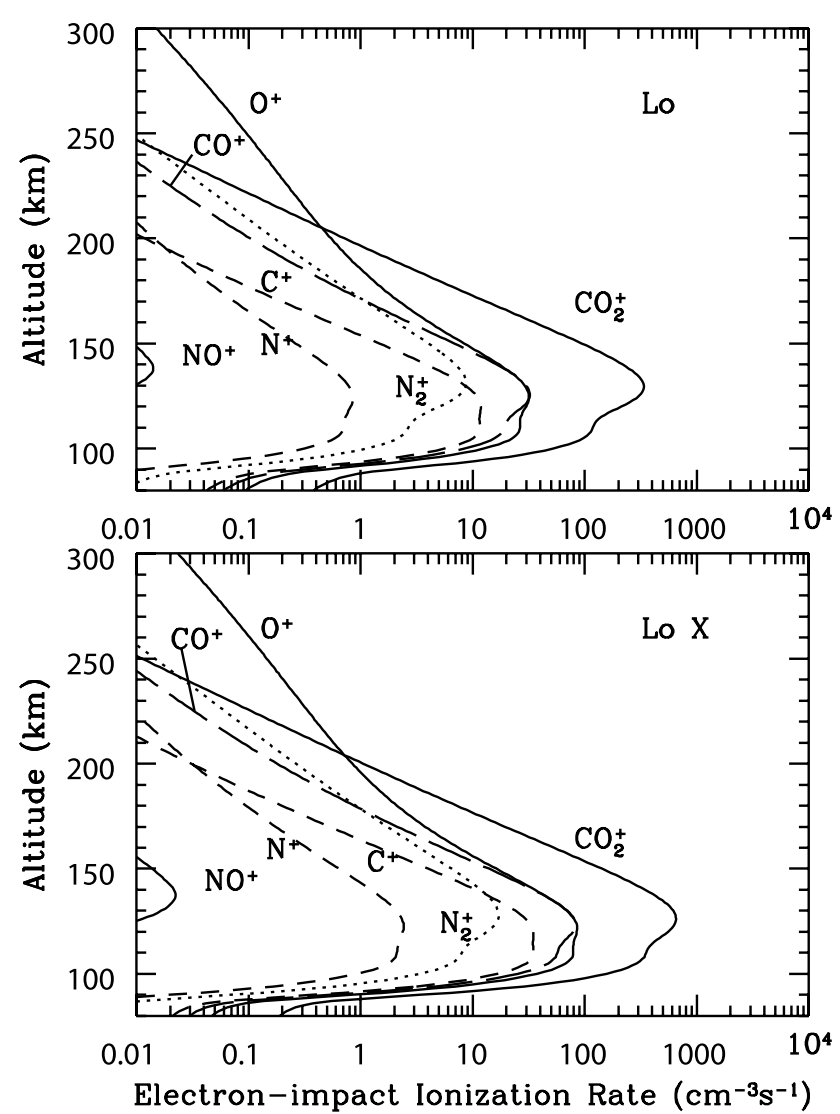

Figure 5. Altitude profiles of the production rates by electron-impact ionization of seven ions for the low solar activity models. (top) Standard model ("Lo"). (bottom) Enhanced X-ray model ("Lo X").

and auger electrons can carry out several ionizations before they are thermalized.

[29] The electron impact production rates of $\mathrm{CO}_{2}^{+}$and $\mathrm{N}_{2}^{+}$ near the main peaks increase from the standard to the enhanced X-ray models by a factor of $\sim 2$ at low solar activity and by a factor of $\sim 3.4$ at high solar activity. The peak electron-impact production rates of species that are sensitive to higher energy electrons, such as $\mathrm{O}^{+}, \mathrm{CO}^{+}, \mathrm{C}^{+}$, and $\mathrm{N}^{+}$, would be expected to increase by larger factors. Indeed, as Table 3 shows, the predicted increases of maximum production from the standard to the enhanced X-ray models for these ions is in the range 2.6-2.9 at low solar activity, and in the range $4.6-6$ at high solar activity.

[30] A more distinct lower peak or shoulder appears in the altitude profile of the electron-impact production rates for the enhanced soft X-ray models than for the standard models. Thus when the soft X-ray flux is enhanced, the ratio of the upper peak to lower shoulder is smaller. These ratios for production of $\mathrm{CO}_{2}^{+}$and $\mathrm{N}_{2}^{+}$by electron-impact ionization are in the range $2-3$ for the standard models. For the enhanced X-ray models, the lower peak is relatively larger, with upper to lower peak ratios of 1.2-2.1.

[31] Because they arise from multiple sources and are more sensitive to higher energy electrons, the maxima in the electron impact production rate profiles of $\mathrm{CO}^{+}, \mathrm{O}^{+}, \mathrm{C}^{+}$and $\mathrm{N}^{+}$are broad, with smaller ratios of upper peaks to lower shoulders. For $\mathrm{O}^{+}$and $\mathrm{N}^{+}$, the upper peaks are comparable to the lower peaks at low solar activity; for $\mathrm{C}^{+}$, the peaks converge into a single maximum at low altitudes, as do the $\mathrm{O}^{+}$and $\mathrm{N}^{+}$peaks at high solar activity.

[32] Near the main peak, a larger fraction of the ionization is produced by solar photons than by electron-impact ionization; the lower shoulder is dominated by electronimpact ionization. Because the photoproduction rates of $\mathrm{O}^{+}$, $\mathrm{CO}^{+}, \mathrm{C}^{+}$, and $\mathrm{N}^{+}$are more sensitive to shorter wavelength photons and to higher energy electrons, we expect the upper peaks in the photo- and electron impact production rates of these ions should appear lower in the thermosphere, where the higher energy photons penetrate. This is indeed what we find. Like the $\mathrm{CO}_{2}^{+}$production profiles, however, the upper peak is dominated by photoproduction and the lower peak or shoulder by electron-impact production.

\section{Ion and Electron Density Profiles}

[33] The computed density profiles for the electrons and for ions that peak at lower altitudes, including $\mathrm{O}_{2}^{+}, \mathrm{CO}_{2}^{+}$, and $\mathrm{NO}^{+}$, are presented in Figures 7 and 8 at low and high solar activities, respectively, for both the standard and enhanced soft X-ray models. Also shown are the density profiles for $\mathrm{O}^{+}$, which peak above $200 \mathrm{~km}$. The altitudes and magnitudes of the $E, F_{1}, \mathrm{CO}_{2}^{+}, \mathrm{O}_{2}^{+}$, and $\mathrm{O}^{+}$peaks are summarized in Table 4. The low solar activity profiles of $\mathrm{O}_{2}^{+}, \mathrm{CO}_{2}^{+}$, and $\mathrm{O}^{+}$are compared to the measured values from the Viking

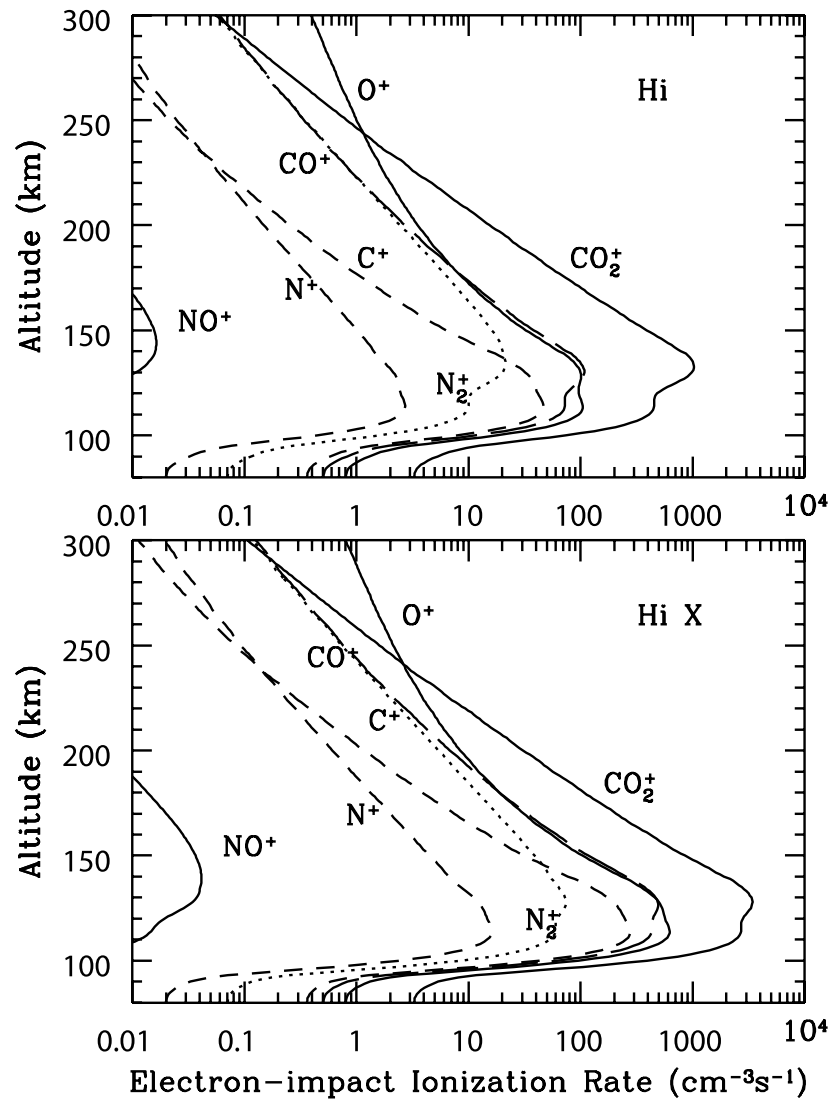

Figure 6. Altitude profiles of the production rates by electron-impact ionization of seven ions for the high solar activity models. (top) Standard model ("Hi"). (bottom) Enhanced X-ray model ("Hi X”). 
Table 3. Peak Production Rates and Altitudes Due to Electron Impact Ionization for the Low and High Solar Activity Standard and Enhanced X-Ray Models

\begin{tabular}{|c|c|c|c|c|c|}
\hline Species & $\begin{array}{c}\text { Altitude, } \\
\text { km }\end{array}$ & $\begin{array}{l}\text { Production } \\
\text { Rate, } \\
\mathrm{cm}^{-3} \mathrm{~s}^{-1}\end{array}$ & $\begin{array}{c}\text { Altitude, } \\
\text { km }\end{array}$ & $\begin{array}{l}\text { Production } \\
\text { Rate, } \\
\mathrm{cm}^{-3} \mathrm{~s}^{-1}\end{array}$ & Ratio \\
\hline \multicolumn{6}{|c|}{ Low Standard and Enhanced X-Ray Models } \\
\hline \multirow{2}{*}{$\mathrm{CO}_{2}^{+}$} & 132 & $3.3(2)^{\mathrm{b}}$ & 126 & $6.5(2)$ & 2.0 \\
\hline & 110.5 & $1.19(2)$ & 110.5 & $3.6(2)$ & 3.0 \\
\hline \multirow[t]{2}{*}{$\mathrm{N}_{2}^{+}$} & 131 & $8.8(0)$ & 128 & 1.71(1) & 2.0 \\
\hline & 110.5 & $2.7(0)$ & 110.5 & $8.1(0)$ & 3.0 \\
\hline \multirow[t]{2}{*}{$\mathrm{O}^{+}$} & 125 & $3.2(1)$ & 121.0 & $8.5(1)$ & 2.7 \\
\hline & 110.5 & $2.6(1)$ & 110.5 & $7.9(1)$ & 3.0 \\
\hline \multirow[t]{2}{*}{$\mathrm{CO}^{+}$} & 125 & $3.2(1)$ & 123.5 & $8.3(1)$ & 2.6 \\
\hline & 111.5 & $1.95(1)$ & 110.5 & $5.7(1)$ & 2.9 \\
\hline \multirow[t]{2}{*}{$\mathrm{C}^{+}$} & 119 & $1.18(1)$ & 118.5 & $3.5(1)$ & 2.9 \\
\hline & 110.5 & $1.17(1)$ & 110.5 & $3.5(1)$ & 3.0 \\
\hline \multirow[t]{2}{*}{$\mathrm{N}^{+}$} & 124 & $8.5(-1)$ & 122.5 & $2.4(0)$ & 2.8 \\
\hline & 111.5 & $7.1(-1)$ & 111.5 & $2.1(0)$ & 3.0 \\
\hline \multirow[t]{2}{*}{$\mathrm{NO}^{+}$} & 138 & $1.41(-2)$ & 137.5 & $2.2(-2)$ & 1.6 \\
\hline & 109.5 & $3.9(-4)$ & 109.5 & $1.10(-3)$ & 2.8 \\
\hline \multicolumn{6}{|c|}{ High Standard and Enhanced X-Ray Models } \\
\hline \multirow[t]{2}{*}{$\mathrm{CO}_{2}^{+}$} & 132.5 & $1.03(3)$ & 128 & $3.4(3)$ & 3.3 \\
\hline & 116.5 & $4.5(2)$ & 115 & $2.7(3)$ & 6.0 \\
\hline \multirow[t]{2}{*}{$\mathrm{N}_{2}^{+}$} & 134.5 & $2.1(1)$ & 128 & $7.4(1)$ & 3.5 \\
\hline & 116.5 & $1.0(1)$ & 115.5 & $6.0(1)$ & 6.0 \\
\hline $\mathrm{O}^{+}$ & 115 & $1.03(2)$ & 114 & $6.2(2)$ & 6.1 \\
\hline \multirow[t]{2}{*}{$\mathrm{CO}^{+}$} & 130.5 & $1.08(2)$ & 126.5 & $4.9(2)$ & 4.6 \\
\hline & 116.5 & $7.2(1)$ & 115.5 & $4.3(2)$ & 6.0 \\
\hline $\mathrm{C}^{+}$ & 114 & $4.7(1)$ & 114 & $2.8(2)$ & 6.0 \\
\hline $\mathrm{N}^{+}$ & 114 & $2.7(0)$ & 114 & $1.6(1)$ & 6.0 \\
\hline \multirow[t]{2}{*}{$\mathrm{NO}^{+}$} & 144 & $1.64(-2)$ & 139 & $4.1(-2)$ & 2.5 \\
\hline & 114.5 & $2.7(-3)$ & 115.5 & $1.58(-2)$ & 5.8 \\
\hline
\end{tabular}

${ }^{\mathrm{a}}$ Ratio of peak production rates for the enhanced X-ray model to those of the standard model.

${ }^{\mathrm{b}} \mathrm{Read}$ as $3.3 \times 10^{2}$.

Retarding Potential Analyzer [Hanson et al., 1977]. The high solar activity electron density profiles are compared with the Mariner 6 ingress profiles [Fjeldbo et al., 1970]. As explained previously, owing to the zero flux upper boundary conditions, the high altitude ion densities should be considered as upper limits. The photochemical equilibrium boundary of $\mathrm{O}^{+}$is near its peak density, which is located at $\sim 220 \mathrm{~km}$ at low solar activity and at $\sim 255 \mathrm{~km}$ at high solar activity. Vertically or horizontally flowing $\mathrm{O}^{+}$ions will reduce the computed densities at and above the peaks. This study is focused on the region near the electron density peaks, which are found below $145 \mathrm{~km}$, and relative densities at high altitudes are more accurate than the absolute values.

[34] The $F_{1}$ peak for both standard and enhanced soft $\mathrm{X}$-ray models is found in the range $136-137 \mathrm{~km}$ at low solar activity, and from 137-139 km at high solar activity. Both the low and high solar activity models also show a lower shoulder below the major $n_{e}$ peak, which appears near $110 \mathrm{~km}$ at low solar activity and near $115 \mathrm{~km}$ at high solar activity and is identified as the $E$-region peak. The $F_{1}$ peak appears lower in the ionosphere for both enhanced X-ray models. The fraction of ionization due to soft $\mathrm{X}$ rays and their associated high energy photoelectrons is larger in these models, thus moving the altitude of the maximum density to lower altitudes. The effect is more pronounced at high solar activity because the soft $X$ rays were increased by a larger factor at high solar activity than those at low solar activity.

[35] The $F_{1}$ electron density peaks at low solar activity are about $8.7 \times 10^{4}$ and $9.5 \times 10^{4} \mathrm{~cm}^{-3}$, for the standard and enhanced soft X-ray models, respectively. The analogous values at high solar activity are $1.6 \times 10^{5}$ and $2.0 \times$ $10^{5} \mathrm{~cm}^{-3}$, respectively. This represents an increase of only $10 \%$ for the low solar activity model, but a larger $25 \%$ increase at high solar activity. At low solar activity, the $E$-region peak electron density increases by a factor of 1.8 , from $2.4 \times 10^{4}$ to $4.3 \times 10^{4} \mathrm{~cm}^{-3}$; at high solar activity, it increases by a factor of about 2.5 , from $4.7 \times 10^{4}$ to $1.18 \times$ $10^{5} \mathrm{~cm}^{-3}$, from the standard to enhanced X-ray models. As expected from Chapman [1931] theory, these factors are approximately equal to the square roots of 3 and 6 , the factors by which the soft X-ray fluxes are increased.

[36] The $\mathrm{O}^{+}$profile exhibits peaks near $219 \mathrm{~km}$ and $245-$ $256 \mathrm{~km}$ at low and high solar activities, respectively. $\mathrm{O}^{+}$ does not produce a visible $F_{2}$ peak on Mars because the $\mathrm{O}^{+}$ density is at all altitudes less than that of the major ion $\mathrm{O}_{2}^{+}$. The $\mathrm{O}^{+}$peak densities for the standard and enhanced X-ray
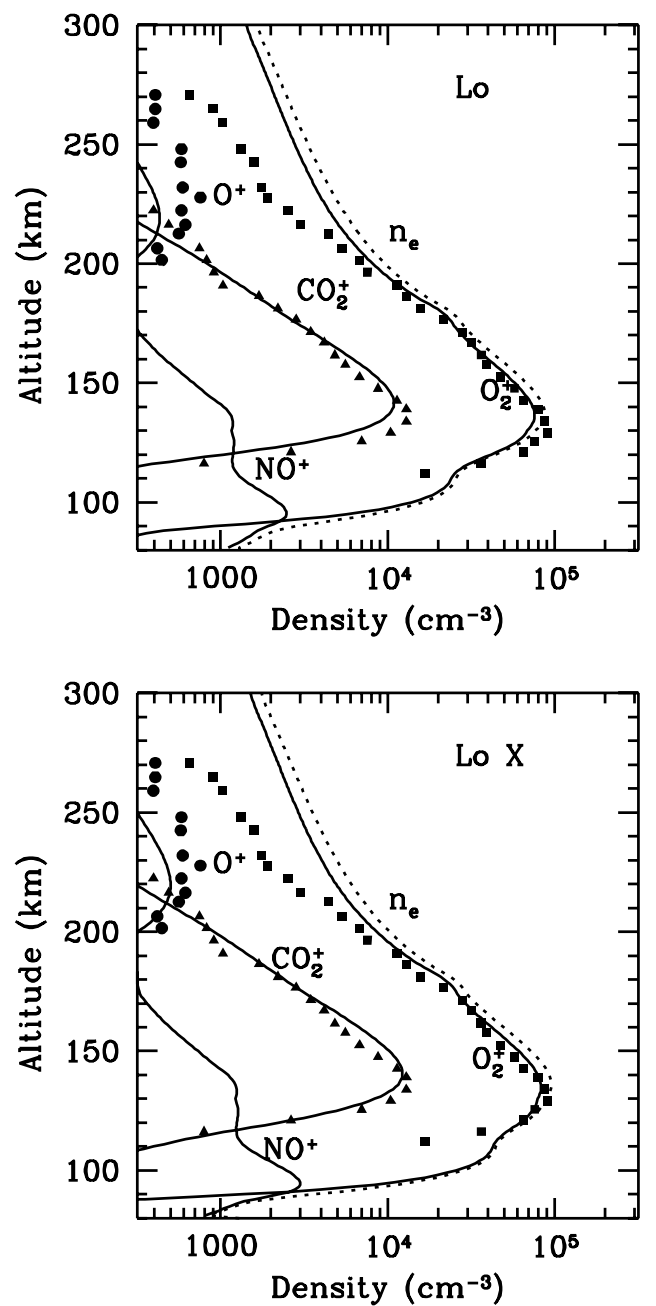

Figure 7. Altitude profiles of the steady state number densities of electrons and four major ions: $\mathrm{O}_{2}{ }^{+}, \mathrm{CO}_{2}{ }^{+}, \mathrm{O}^{+}$, and $\mathrm{NO}^{+}$for the low solar activity standard and enhanced $\mathrm{X}$-ray models. The measured densities from Viking 1 of $\mathrm{O}_{2}{ }^{+}, \mathrm{CO}_{2}{ }^{+}$, and $\mathrm{O}^{+}$are shown as solid squares, triangles, and circles, respectively [Hanson et al., 1977]. (top) Standard low solar activity model ("Lo"). (bottom) Enhanced X-ray model ("Lo X"). 

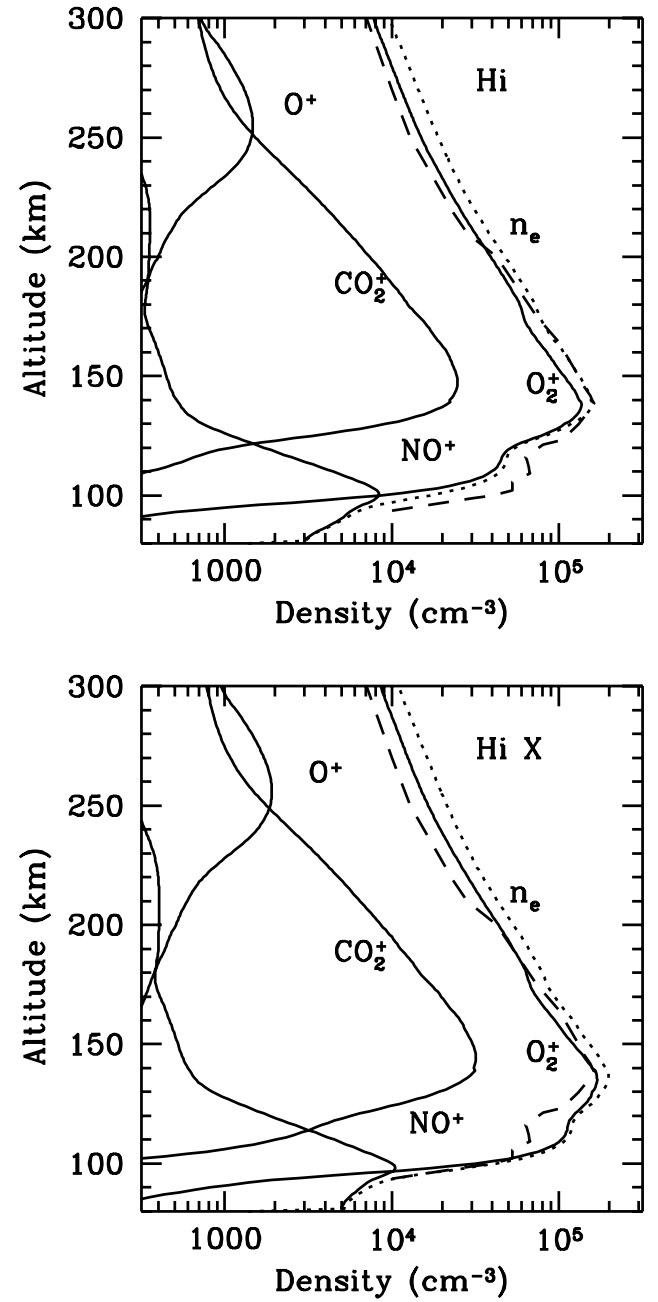

Figure 8. Altitude profiles of the steady state number densities of electrons and four major ions: $\mathrm{O}_{2}{ }^{+}, \mathrm{CO}_{2}{ }^{+}, \mathrm{O}^{+}$, and $\mathrm{NO}^{+}$for the high solar activity standard and enhanced $\mathrm{X}$-ray models. The electron density profiles are compared to the Mariner 6 ingress profile, which is represented as a longdashed curve. (top) Standard high solar activity model ("Hi"). (bottom) Enhanced X-ray model ("Hi X").

models are $4.3 \times 10^{2}$ and $5.0 \times 10^{2} \mathrm{~cm}^{-3}$, respectively at low solar activity, and $1.47 \times 10^{3}$ and $1.9 \times 10^{3} \mathrm{~cm}^{-3}$, respectively, at high solar activity. With enhanced soft X-ray fluxes, the peak densities increase by $\sim 15-30 \%$.

[37] Because the models pertained to solar zenith angles of $60^{\circ}$, and to the average sun-Mars distance of $1.52 \mathrm{AU}$, only a rough comparison to the densities derived from the Viking RPA data is appropriate [Hanson et al., 1977]. Viking 1 entered the Martian atmosphere at a solar zenith angle of $44^{\circ}$, and at a heliocentric distance of $1.648 \mathrm{AU}$. In addition, the exospheric temperature $\left(T_{\infty}\right)$ is about $200 \mathrm{~K}$ in our low solar activity model, whereas the Viking exospheric temperature appears to be somewhat less. The temperatures derived from the Viking 1 and 2 landers show wave-like structure that makes identification of $T_{\infty}$ difficult [Nier and McElroy, 1977]. The overall effect is that peaks in the photoionization production rate profiles in our low solar activity models should be slightly smaller and occur slightly higher in the atmosphere than those for models based on the conditions of Viking. At altitudes where the solar fluxes are optically thin, such as near the $\mathrm{O}^{+}$peak, the production rates for different solar zenith angles should be roughly equal. Although the noise in the Viking 1 measured $\mathrm{O}^{+}$density profile is about $20 \%$, the magnitude of the measured $\mathrm{O}^{+}$ peak density is $\sim 7.5 \times 10^{2} \mathrm{~cm}^{-3}$, which is larger by $\sim 70 \%$, and $\sim 50 \%$ than those of the low solar activity standard and enhanced X-ray models, respectively. Thus, enhancing the soft X-ray flux appears to increase the $\mathrm{O}^{+}$densities somewhat. Although Fox [1993] reproduced the Viking peak value of $\mathrm{O}^{+}$in a model that included upward velocity boundary conditions for the ions, the neutral model was based on measurements of the Viking neutral mass spectrometer [e.g., Nier and McElroy, 1976, 1977], and the model contained no $\mathrm{H}_{2} \cdot \mathrm{H}_{2}$ destroys $\mathrm{O}^{+}$in the reaction

$$
\mathrm{O}^{+}+\mathrm{H}_{2} \rightarrow \mathrm{OH}^{+}+\mathrm{H}
$$

As stated above, we have assumed here that the $\mathrm{H}_{2}$ mixing ratio is 15 ppm, as derived by Krasnopolsky and Feldman [2001]. Fox [2001, 2003a] showed that, owing to similar reactions with $\mathrm{H}_{2}$, the density profiles of $\mathrm{O}^{+}, \mathrm{CO}_{2}^{+}, \mathrm{N}_{2}^{+}$, and $\mathrm{CO}^{+}$are greatly affected by the assumed mixing ratio of $\mathrm{H}_{2}$ for abundances greater than about $4 \mathrm{ppm}$. The Mars ionosphere model of Fox and Bakalian [2001] was constructed with a mixing ratio of $40 \mathrm{ppm} \mathrm{H}_{2}$, which was the previously accepted value that was based on the Mars Lyman alpha measurements of Krasnopolsky et al. [1998]. The $\mathrm{O}^{+}$peak in the density profile in this model, $\sim 300 \mathrm{~cm}^{-3}$, was in serious disagreement with the Viking measured value.

[38] The peak densities and altitudes of $\mathrm{O}^{+}, \mathrm{N}_{2}^{+}$, and $\mathrm{CO}^{+}$ decrease significantly as the $\mathrm{H}_{2}$ mixing ratio increases. Since the density of $\mathrm{CO}_{2}^{+}$peaks at low altitudes, it is not much affected by the $\mathrm{H}_{2}$ mixing ratio; reaction with $\mathrm{H}_{2}$ is a major loss process for $\mathrm{CO}_{2}^{+}$principally at high altitudes. A smaller mixing ratio of $\mathrm{H}_{2}$ or a larger $\mathrm{O}$ abundance could bring the model $\mathrm{O}^{+}$density profiles into better agreement with the Viking measured values [Fox, 2001, 2003a]. There is, however, no other evidence for a larger $\mathrm{O}$ abundance at low solar activity. In fact, Stewart et al. [1992] derived an even lower $\mathrm{O}$ abundance of $\sim 0.7 \%$ at the ion peak from an

Table 4. Effect of Enhanced Soft X Rays on Peak Ion Densities ${ }^{a}$

\begin{tabular}{|c|c|c|c|c|}
\hline Peak & $\begin{array}{c}\text { Altitude, } \\
\text { km }\end{array}$ & $\begin{array}{l}\text { Standard } \\
\text { X Rays }\end{array}$ & $\begin{array}{c}\text { Enhanced }^{b} \\
\text { X Rays }\end{array}$ & Ratio \\
\hline \multicolumn{5}{|c|}{ Low Solar Activity } \\
\hline $\mathrm{O}^{+}$ & $219-220$ & $4.3 \times 10^{2}$ & $5.0 \times 10^{2}$ & 1.16 \\
\hline $\mathrm{O}_{2}^{+}$ & $135-136$ & $7.6 \times 10^{4}$ & $8.3 \times 10^{4}$ & 1.10 \\
\hline $\mathrm{CO}_{2}^{+}$ & $140-141$ & $1.11 \times 10^{4}$ & $1.23 \times 10^{4}$ & 1.11 \\
\hline$E$ & $109-110$ & $2.4 \times 10^{4}$ & $4.3 \times 10^{4}$ & 1.79 \\
\hline$F_{1}$ & $135-137$ & $8.7 \times 10^{4}$ & $9.5 \times 10^{4}$ & 1.10 \\
\hline \multicolumn{5}{|c|}{ High Solar Activity } \\
\hline $\mathrm{O}^{+}$ & $255-256$ & $1.47 \times 10^{3}$ & $1.91 \times 10^{3}$ & 1.30 \\
\hline $\mathrm{O}_{2}^{+}$ & $135-139$ & $1.36 \times 10^{5}$ & $1.70 \times 10^{5}$ & 1.25 \\
\hline $\mathrm{CO}_{2}^{+}$ & $145-147$ & $2.5 \times 10^{4}$ & $3.2 \times 10^{4}$ & 1.28 \\
\hline E & $114-115$ & $4.7 \times 10^{4}$ & $1.18 \times 10^{5}$ & 2.5 \\
\hline$F_{1}$ & $137-139$ & $1.6 \times 10^{5}$ & $2.0 \times 10^{5}$ & 1.25 \\
\hline
\end{tabular}

${ }^{\mathrm{a}}$ Units are in $\mathrm{cm}^{-3}$

${ }^{b}$ Photon fluxes with wavelengths between 18 and $200 \AA$ multiplied by a factor of 3 at low solar activity and by a factor of 6 at high solar activity. 
analysis of the intensities at $1304 \AA$ made by the Mariner 9 ultraviolet spectrometer. The considerable discrepancy between these measurements and those derived from the Viking measured ion density profiles has not been addressed. As mentioned previously, it has been suggested that winds and eddy diffusion may act to limit the variations of the thermospheric mixing ratio of $\mathrm{O}$ over a solar cycle [Bougher et al., 2000].

[39] The $\mathrm{O}_{2}^{+}$profiles show that the density peak is considerably broadened and both the upper peak and lower shoulder, and the region between them are larger for the enhanced X-ray models. As Table 4 shows, that for low solar activity, the $\mathrm{O}_{2}^{+}$density at the upper peaks increase by $\sim 10 \%$ from $7.6 \times 10^{4}$ to $8.3 \times 10^{4} \mathrm{~cm}^{-3}$ at 136 and $135 \mathrm{~km}$, from the standard to the enhanced X-ray models. The Viking RPA placed the maximum density of $\mathrm{O}_{2}^{+}$near $130 \mathrm{~km}$, with a magnitude of $9.0 \times 10^{4} \mathrm{~cm}^{-3}$ [Hanson et al., 1977]. Chapman theory shows that as the solar zenith angle increases, the altitude of the molecular ion peaks also rise. We find that as the solar zenith angle changes from the Viking value of $44^{\circ}$ to the $60^{\circ}$ of our standard model, the $\mathrm{O}_{2}^{+}$ density maxima should decrease by a factor of about 1.2 to $7.5 \times 10^{4} \mathrm{~cm}^{-3}$, and the altitude of the peak should rise by about $3 \mathrm{~km}$. If the model value for $T_{\infty}$ of about $200 \mathrm{~K}$ were decreased to about $180 \mathrm{~K}$, the ion peak should appear somewhat lower also. Thus, although the peak in the Viking $\mathrm{O}_{2}^{+}$altitude profile is $\sim 5 \mathrm{~km}$ lower than that of our model, when the differences in and uncertainties of the model are taken into account, the altitude and magnitude of the adjusted Viking peak density compares favorably with that of the low solar activity standard model. The discrepancy with the Viking model is larger for the enhanced X-ray model.

[40] The computed $\mathrm{CO}_{2}^{+}$main peak densities are $1.11 \times$ $10^{4} \mathrm{~cm}^{-3}$ at $141 \mathrm{~km}$ and $1.23 \times 10^{4} \mathrm{~cm}^{-3}$ at $140 \mathrm{~km}$ for the low solar activity standard and enhanced soft X-ray models, respectively. The $\mathrm{CO}_{2}^{+}$densities reported by Viking maximize in the range 134 to $139 \mathrm{~km}$, with a value of about 1.3 $\times 10^{4} \mathrm{~cm}^{-3}$. When the larger solar zenith angles assumed in the model compared to that of Viking is taken into account, this density is in acceptable agreement with that of the standard low solar activity model, but is slightly too large in the enhanced X-ray model. The difference between the standard and enhanced $\mathrm{X}$-ray model $\mathrm{CO}_{2}^{+}$density peaks is, however, only about $12 \%$, and is within the uncertainties of the measurements and models.

[41] Since $\mathrm{O}_{2}^{+}$is the major molecular ion and it is destroyed mostly by dissociative recombination, the $\mathrm{O}_{2}^{+}$ density peaks near the altitude of maximum ion production, as Chapman theory would predict. $\mathrm{CO}_{2}^{+}$, however, peaks 5$8 \mathrm{~km}$ higher in the atmosphere because it is destroyed preferentially by reaction with $\mathrm{O}$ :

$$
\mathrm{CO}_{2}^{+}+\mathrm{O} \rightarrow \mathrm{O}_{2}^{+}+\mathrm{CO}
$$

and

$$
\mathrm{CO}_{2}^{+}+\mathrm{O} \rightarrow \mathrm{CO}_{2}+\mathrm{O}^{+}
$$

rather than by dissociative recombination. As stated previously, the mixing ratio of $\mathrm{O}$ at low solar activity has been assumed to be 0.02 at $130 \mathrm{~km}$. Larger $\mathrm{O}$ abundances would decrease the density of $\mathrm{CO}_{2}^{+}$relative to that of $\mathrm{O}_{2}^{+}$, and raise the altitude of the $\mathrm{CO}_{2}^{+}$peak. If in situ density profiles, preferably measured by an ion mass spectrometer, were available, the altitude difference between the $\mathrm{O}_{2}^{+}$and $\mathrm{CO}_{2}^{+}$peaks, in addition to the relative densities, could be used to infer the $\mathrm{O}$ abundances.

[42] At high solar activity, the peak $\mathrm{CO}_{2}^{+}$densities are $2.5 \times 10^{4}$ at $147 \mathrm{~km}$, and $3.2 \times 10^{4} \mathrm{~cm}^{-3}$ at $145 \mathrm{~km}$, for the standard and enhanced X-ray models, respectively. This increase by a factor of 1.3 , like that of $\mathrm{O}_{2}^{+}$, is larger than that at low solar activity, due to the larger factor by which the solar fluxes below $200 \AA$ are assumed to increase in the high solar activity model. The lower shoulder in the $\mathrm{CO}_{2}^{+}$density profiles appears near 110 $\mathrm{km}$ at low solar activity and near $116 \mathrm{~km}$ at high solar activity. When the soft $\mathrm{X}$ rays are enhanced in the low solar activity model, the magnitude of the lower peak increases by a factor of about 3. At high solar activity, the lower peak density increases by a factor of 5.7. Unlike the lower shoulders in the $\mathrm{O}_{2}^{+}$and electron density profiles, which increase by approximately the square root of the factor by which the soft X-ray photon fluxes are assumed to increase, these increases are approximately linearly proportional to this factor. Thus if in situ measurements of $\mathrm{CO}_{2}^{+}$densities near the lower peaks were available, they could be used as an independent indicator of the magnitude of the soft $\mathrm{X}$ rays. Remote sensing measurements of $\mathrm{CO}_{2}^{+}$are difficult. The major emissions of $\mathrm{CO}_{2}^{+}$in the ultraviolet are the $A^{2} \Pi_{u} \rightarrow X^{2} \Pi_{g}$ Fox-Duffendack-Barker bands, and the $B^{2} \Sigma_{u}^{+} \rightarrow X^{2} \Pi_{g}$ ultraviolet doublet. These emissions are produced mainly in photoionization and electron impact ionization of $\mathrm{CO}_{2}$, and thus are not indicative of the ambient densities of $\mathrm{CO}_{2}^{+}$[cf. Fox, 1992]. Only the production rate due to fluorescent scattering by $\mathrm{CO}_{2}^{+}$is sensitive to the absolute $\mathrm{CO}_{2}^{+}$densities. Very little of either feature is produced by this source, and the existing limb profiles of the intensities from the Mariner ultraviolet spectrometer went off-scale at altitudes above the peak [e.g., Stewart, 1972]. Mixing of the $\mathrm{CO}_{2}^{+} A$ and $B$ states prior to radiation makes interpretation of the spectra even more difficult. There are infrared emission features of $\mathrm{CO}_{2}^{+}$at 500,1283 , and $1469 \mathrm{~cm}^{-1}$ (R. Sharma, private communication, 2004) [see also Gauyacq et al., 1979]. If any of these emissions arising from the Martian lower thermosphere were detectable either from the ground or from orbiting spacecraft, the magnitude of the soft X-ray variability could be better constrained. Although all the ions exhibit lower shoulders, none of the other ion densities at these low altitudes is predicted to be large enough to be measurable.

[43] $\mathrm{The} \mathrm{NO}^{+}$density profile exhibits only one peak in the range $94-95 \mathrm{~km}$ at low solar activity and at $98-100 \mathrm{~km}$ at high solar activity, although there is a hint of a lower shoulder about $5 \mathrm{~km}$ below the main peak. For both models, the $\mathrm{NO}^{+}$peak densities increase by approximately $20 \%$ from the standard to the enhanced X-ray models. $\mathrm{NO}^{+}$ becomes the major ion just below the density peaks. Since NO is a minor constituent of the Martian atmosphere, chemical reactions rather than direct ionization of NO determine its density profile. Furthermore, since NO has the lowest ionization potential of all the species in the model, in regions where there are a sufficient number of 

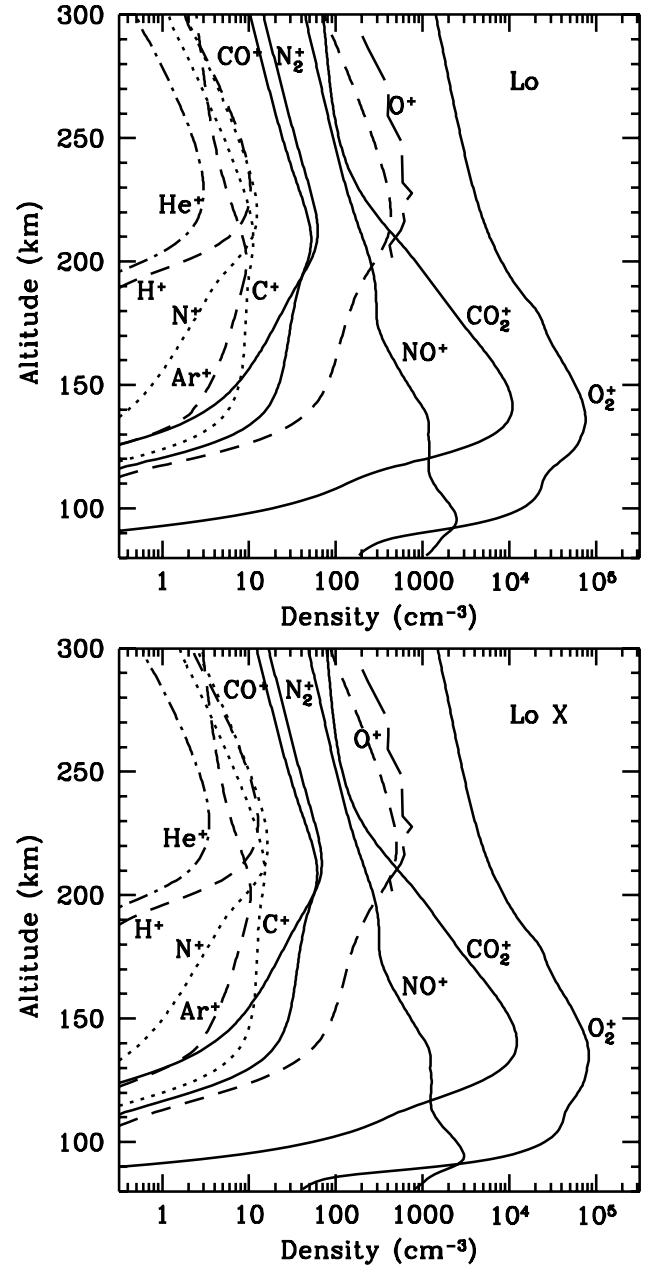

Figure 9. Altitude profiles of the steady state number densities of eleven ions: $\mathrm{O}_{2}^{+}, \mathrm{CO}_{2}^{+}, \mathrm{NO}^{+}, \mathrm{O}^{+}, \mathrm{N}_{2}^{+}, \mathrm{CO}^{+}$, $\mathrm{C}^{+}, \mathrm{Ar}^{+}, \mathrm{N}^{+}, \mathrm{H}^{+}$, and $\mathrm{He}^{+}$for the low solar activity standard and enhanced X-ray models. The densities of $\mathrm{O}^{+}\left({ }^{2} D\right)$, $\mathrm{O}^{+}\left({ }^{2} P\right)$, and $\mathrm{O}^{++}$were computed, but are not shown in this figure. The $\mathrm{O}^{+}$profile is the sum of the densities of the ground and metastable states. The $\mathrm{O}^{+}$densities measured by the Viking RPA are represented by the long dashed curve and are shown for comparison [Hanson et al., 1977]. (top) Standard model ("Lo"). (bottom) Enhanced X-ray model ("Lo X").

collisions, almost all ionization produces $\mathrm{NO}^{+}$eventually. Near its peak the major production reaction of $\mathrm{NO}^{+}$is

$$
\mathrm{O}_{2}^{+}+\mathrm{N}_{2} \rightarrow \mathrm{NO}^{+}+\mathrm{NO},
$$

if its rate coefficient is near the upper limit of $1 \times$ $10^{-15} \mathrm{~cm}^{3} \mathrm{~s}^{-1}$. Otherwise the most important reaction is [Ferguson, 1973]

$$
\mathrm{O}_{2}^{+}+\mathrm{N} \rightarrow \mathrm{NO}^{+}+\mathrm{O},
$$

which has been found to proceed at nearly gas kinetic rates.

[44] The ion density profiles for all the ions from 80 to $300 \mathrm{~km}$ are shown in Figures 9 and 10 for the standard and enhanced X-ray models at low and high solar activity, respectively. As has been found previously for Venus and Mars, and as these figures demonstrate, the composition of the ionosphere changes from low to high solar activity, with the densities of atomic ions increasing relative to molecular ions [cf. Fox and Sung, 2001; Fox et al., 1995].

[45] The $\mathrm{C}^{+}$and $\mathrm{N}^{+}$density profiles both peak at altitudes above $240 \mathrm{~km}$, where our models, with zero-flux upper boundary conditions, predict more accurate relative densities than absolute values. The peak densities increase by factors of about 1.35 to 1.65 from the standard to enhanced soft X-ray models. The increases from low to high solar activity are factors of 3.2-5.5 for $\mathrm{C}^{+}$and 3.2-3.9 for $\mathrm{N}^{+}$ [cf. Fox et al., 1995]. The $\mathrm{C}^{+}$density profiles exhibit broad, flat regions between 140 and $200 \mathrm{~km}$ in all the models. Just as for Venus, this structure appears because $\mathrm{C}^{+}$is produced
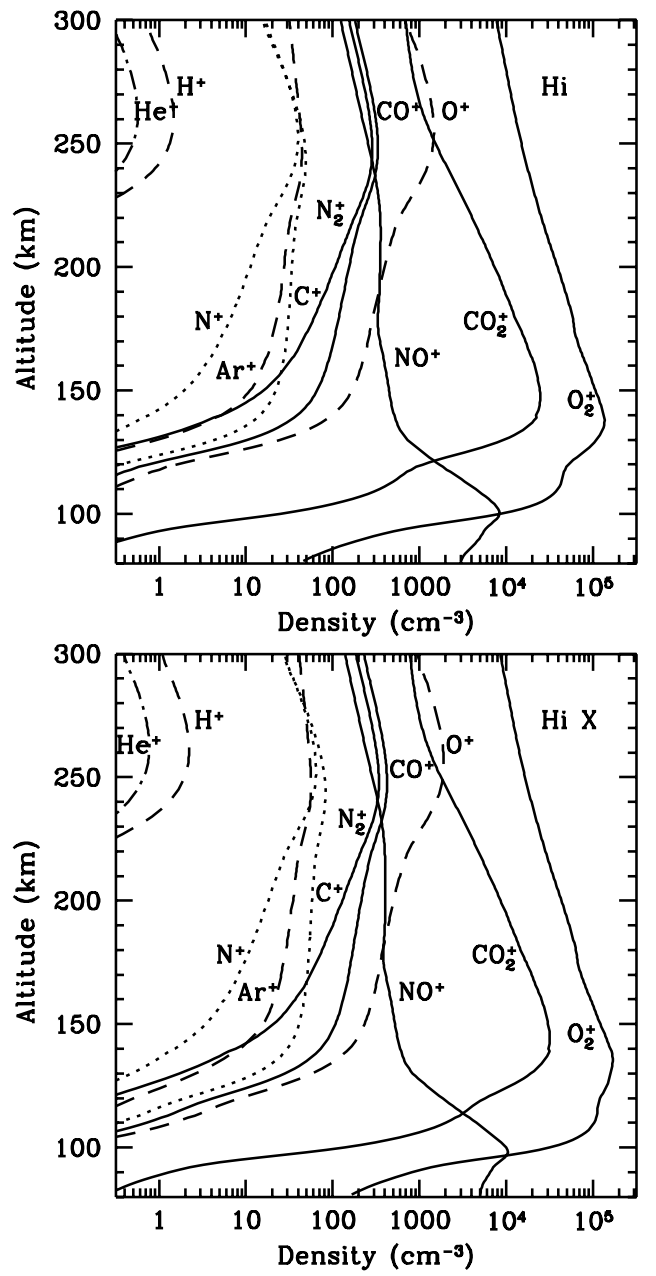

Figure 10. Altitude profiles of the steady state number densities of eleven ions: $\mathrm{O}_{2}^{+}, \mathrm{CO}_{2}{ }^{+}, \mathrm{NO}^{+}, \mathrm{O}^{+}, \mathrm{N}_{2}{ }^{+}, \mathrm{CO}^{+}$, $\mathrm{C}^{+}, \mathrm{Ar}^{+}, \mathrm{N}^{+}, \mathrm{H}^{+}$, and $\mathrm{He}^{+}$for the high solar activity standard and enhanced X-ray models. The densities of $\mathrm{O}^{+}\left({ }^{2} D\right)$, $\mathrm{O}^{+}\left({ }^{2} P\right)$, and $\mathrm{O}^{++}$were computed, but are not shown in this figure. The $\mathrm{O}^{+}$profile is the sum of the densities of the ground and metastable states. (top) Standard model ("Hi"). (bottom) Enhanced X-ray model ("Hi X"). 

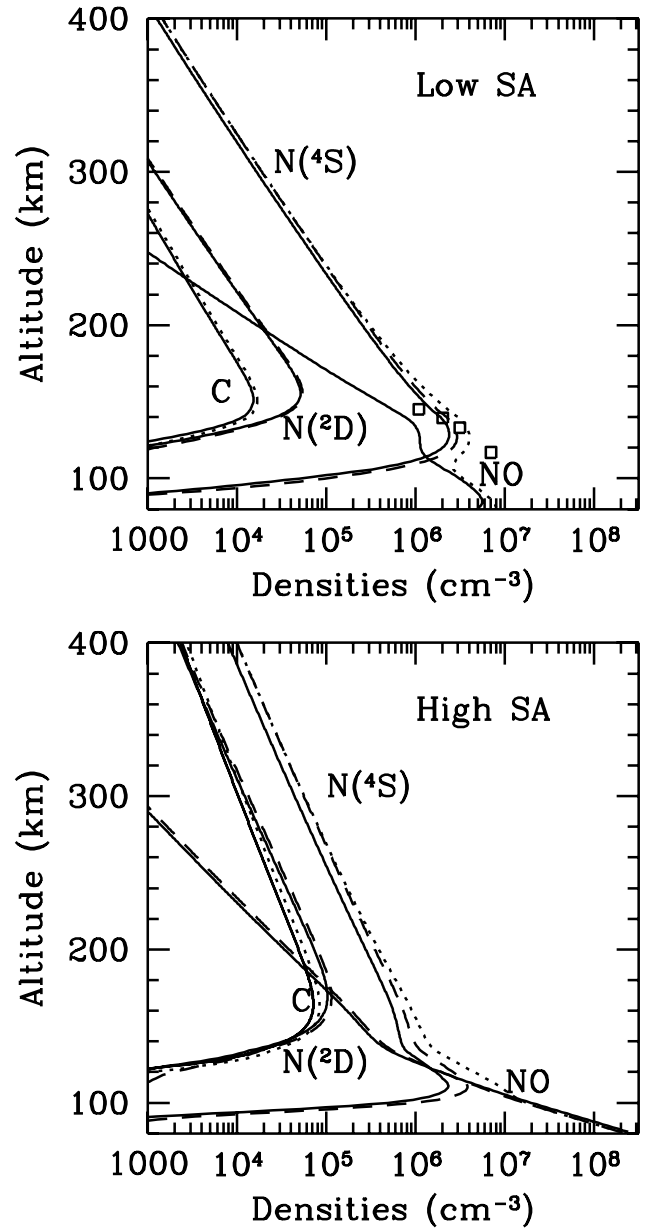

Figure 11. Altitude profiles of the steady state number densities of the minor neutral species $\mathrm{N}\left({ }^{4} S\right), \mathrm{N}\left({ }^{2} D\right), \mathrm{NO}$, and $\mathrm{C}$ for the low and high solar activity standard and enhanced $\mathrm{X}$-ray models. The number densities for the standard model are given as solid curves; those for the enhanced X-ray models are given as dashed ( $\mathrm{N}$ and $\mathrm{NO}$ ) or dotted curves (C). The sum of the $\mathrm{N}$ and $\mathrm{NO}$ densities are also shown as dotted curves. The NO densities measured by Viking 1 are shown as open squares [Nier and McElroy, 1977]. (top) Low solar activity ("Lo SA"). (bottom) High solar activity ("Hi SA").

near and below the peak by dissociative ionization of $\mathrm{CO}_{2}$ and lost by reaction with $\mathrm{CO}_{2}$ :

$$
\mathrm{C}^{+}+\mathrm{CO}_{2} \rightarrow \mathrm{CO}^{+}+\mathrm{CO}
$$

[cf. Dalgarno and Fox, 1994; Fox et al., 1995; Fox and Sung, 2001]. If the $\mathrm{C}^{+}$densities were in photochemical equilibrium (PCE) and the atmosphere were optically thin to ionizing radiation, the $\mathrm{C}^{+}$density would be nearly constant. At high altitudes, the PCE approximation begins to fail, and near and below the $F_{1}$ peak, the atmosphere is no longer optically thin, so the $\mathrm{C}^{+}$density decreases rapidly at low and high altitudes.

[46] Similarly, the predicted $\mathrm{CO}^{+}$profiles are also broad and flat between 160 and $200 \mathrm{~km}$. This is because the major production process for $\mathrm{CO}^{+}$is dissociative ionization of $\mathrm{CO}_{2}$, with some contribution from the reaction of $\mathrm{C}^{+}$ with $\mathrm{CO}_{2}$, and the major loss process is reaction of $\mathrm{CO}^{+}$ with $\mathrm{CO}_{2}$. Just as for $\mathrm{C}^{+}$, if PCE prevailed and the thermosphere were optically thin to ionizing radiation, the $\mathrm{CO}^{+}$density would be nearly constant. At low solar activity, the $\mathrm{CO}^{+}$peak density is near $209 \mathrm{~km}$, and it increases by $\sim 20 \%$ from the standard to the enhanced X-ray model. The high solar activity peak occurs near $248 \mathrm{~km}$, and the increase from the standard to the enhanced X-ray model is $\sim 30 \%$. The factor by which the peak density increases from low to high solar activity is in the range 6.3-6.9.

\section{Minor Neutral Density Profiles}

[47] Results from the SNOE spacecraft showed that the absorption of enhanced fluxes of soft $\mathrm{X}$ rays increased the terrestrial low latitude NO densities, bringing them into substantial agreement with the measured values [e.g., Barth et al., 1999]. We here examine the effects of enhanced X rays on the density profiles of the odd nitrogen species NO, $\mathrm{N}\left({ }^{4} S\right), \mathrm{N}\left({ }^{2} D\right)$, and $\mathrm{N}\left({ }^{2} P\right)$, and the minor species atomic $\mathrm{C}$ in the thermosphere of Mars. Zero flux lower boundary conditions were adopted for $\mathrm{C}$, and downward fluxes for $\mathrm{NO}$ and $\mathrm{N}$. For the metastable species $\mathrm{N}\left({ }^{2} D\right)$ and $\mathrm{N}\left({ }^{2} P\right)$, photochemical equilibrium was assumed at the lower boundary of the model. At the upper boundaries, diffusive equilibrium was assumed. The flux of NO at the lower boundary was taken somewhat arbitrarily to be $-2 \times$ $10^{7} \mathrm{~cm}^{-2} \mathrm{~s}^{-1}$ at low solar activity and $-5 \times 10^{7} \mathrm{~cm}^{-2} \mathrm{~s}^{-1}$ at high solar activity. The flux of $\mathrm{N}$ was taken to be $-1.0 \times$ $10^{2} \mathrm{~cm}^{-2} \mathrm{~s}^{-1}$ at low solar activity and $-1.25 \times 10^{2} \mathrm{~cm}^{-2} \mathrm{~s}^{-1}$ at high solar activity. Both of these fluxes represent downward velocities that are less than the approximate upper limit of $\mathrm{K} / \mathrm{H}$, where $\mathrm{K}$ is the eddy diffusion coefficient and $\mathrm{H}$ is the scale height of the atmosphere, but the fluxes were also constrained by the requirement that the computed densities be positive. No fine tuning was done. Models of the martian middle atmosphere have shown that the thermosphere is a source of $\mathrm{N}$ and NO to the middle atmosphere [e.g., Krasnopolsky, 1993]. Because, however, we have not modeled the middle atmosphere, the density profiles of odd nitrogen species should not be considered accurate below $\sim 90 \mathrm{~km}$, which is about 1.5 scale heights above the lower boundary.

[48] Figure 11 shows the computed low and high solar activity density profiles of these species. The solid curves are the density profiles for the standard models, and the dashed curves are those for the enhanced soft X-ray models. The NO densities measured by the Mass Spectrometer on Viking 1, as reported by Nier and McElroy [1977], are shown in the top panel of Figure 11 as open squares. It is clear that the larger soft X-ray fluxes make little difference for the NO density profiles, but the $\mathrm{N}$ density peaks are larger by $23 \%$ and $65 \%$ when the soft X-ray fluxes are enhanced at low and high solar activities, respectively. For the enhanced X-ray models, the computed peak densities of $\mathrm{N}$ are $2.9 \times 10^{6} \mathrm{~cm}^{-3}$ at $126 \mathrm{~km}$ at low solar activity, and $3.9 \times 10^{6} \mathrm{~cm}^{-3}$ at $111 \mathrm{~km}$ at high solar activity. NO is produced in the lower thermosphere by the reaction

$$
\mathrm{N}\left({ }^{2} D\right)+\mathrm{CO}_{2} \rightarrow \mathrm{NO}+\mathrm{CO},
$$


and by the analogous reaction of ground state $\mathrm{N}$

$$
\mathrm{N}\left({ }^{4} S\right)+\mathrm{CO}_{2} \rightarrow \mathrm{NO}+\mathrm{CO},
$$

if the rate coefficient is close to the value $1 \times 10^{-16} \mathrm{~cm}^{3} \mathrm{~s}^{-1}$, which we have assumed. As discussed by Fox and Sung [2001], only upper limits to the rate coefficients for reaction (10) of about $1.7 \times 10^{-16} \mathrm{~cm}^{3} \mathrm{~s}^{-1}$, are available [cf. Brown and Winkler, 1970; Herron and Huie, 1968]. The rates of both of these NO production reactions increase in the lower thermosphere when the $\mathrm{X}$ rays are enhanced. The rates of the major loss processes for $\mathrm{NO}$, reaction with $\mathrm{N}$, (reaction (1)), and reaction with $\mathrm{O}_{2}^{+}$

$$
\mathrm{O}_{2}^{+}+\mathrm{NO} \rightarrow \mathrm{NO}^{+}+\mathrm{O}_{2}
$$

however, also increase. Thus while the production rates of $\mathrm{NO}$ are enhanced as the soft X-ray fluxes increase, the loss rates also increase, and the densities of NO are relatively insensitive to the soft X-ray fluxes in the model.

[49] When the soft $X$ rays are enhanced, the peak densities of $\mathrm{C}$ increase by $11-18 \%$, and those of $\mathrm{N}\left({ }^{2} D\right)$ by $5-$ $11 \%$, where the larger values are for the high solar activity models. Although Figure 11 does not show the $\mathrm{N}\left({ }^{2} P\right)$ density profiles, the peak densities are predicted to be $330-350 \mathrm{~cm}^{-3}$ near $143 \mathrm{~km}$, and $820-940 \mathrm{~cm}^{-3}$ near $153 \mathrm{~km}$, for the low and high solar activity models, respectively.

[50] There is a long-standing discrepancy in the low solar activity model NO densities and those from Viking 1 in the thermosphere from about 115 to $150 \mathrm{~km}$ [Nier and McElroy, 1976, 1977; McElroy et al., 1976]. NO densities of about $3 \times 10^{6} \mathrm{~cm}^{-3}$ were measured near $135 \mathrm{~km}$, whereas our model values at that altitude are about $1 \times$ $10^{6} \mathrm{~cm}^{-3}$ at low solar activity, with little variation from the standard to enhanced X-ray models. Thus the densities are underestimated when compared with the Viking measurements, but unlike NO in the terrestrial lower thermosphere, the discrepancy cannot be removed by enhancing the soft $X$ rays in the Hinteregger solar spectra. As discussed earlier, the rate coefficient for the reaction of $\mathrm{N}$ with NO that we have adopted actually has a slight negative temperature dependence, while the previously recommended value was temperature-independent. Fox [1994] obtained agreement with the Viking NO densities by adopting a rate coefficient for this reaction with a large positive temperature dependences at the low temperatures of the Martian lower thermosphere, which fall in the range 100-200 K. Such large temperature dependences have been ruled out by recent measurements and calculations. The discrepancy between the measured and model NO densities is therefore actually larger here than in previous models.

[51] Except for the lowest point near $117 \mathrm{~km}$, the Viking and model NO densities could be brought into agreement if the Viking mass spectrometer actually measured the sum of the $\mathrm{N}$ and $\mathrm{NO}$ densities. This could happen if $\mathrm{N}$ and $\mathrm{O}$ recombined inside the instrument. At $135 \mathrm{~km}$, the $\mathrm{N}$ density is $(2.2-2.6) \times 10^{6} \mathrm{~cm}^{-3}$, where the range is from the standard low solar activity to the enhanced X-ray model. Thus the sum of the N and NO densities, about $(3.2-3.6) \times$ $10^{6} \mathrm{~cm}^{-3}$, is in good agreement with the NO densities measured by Viking 1. Although the Viking landers carried open-source Nier-type mass spectrometers, neither $\mathrm{O}$ nor $\mathrm{N}$ densities could be measured in the Martian lower thermosphere. The $\mathrm{O}$ densities derived from the $\mathrm{O}_{2}^{+}$and $\mathrm{CO}_{2}^{+}$ density profiles were substantial and our model density profiles of $\mathrm{N}$ are greater than those of NO. The large measured NO density at $117 \mathrm{~km}$ shown in Figure 11, however, militates against this interpretation.

[52] As Nier and McElroy [1977] show, however, the peak at mass-30 in the Viking mass spectrum is about half due to ${ }^{12} \mathrm{C}^{18} \mathrm{O}$ and half due to NO. The accuracy of the derived NO densities therefore depends on the accuracy with which the ${ }^{12} \mathrm{C}^{18} \mathrm{O}$ contribution can be determined. In addition, the Viking mass spectrometers were not calibrated in the laboratory for NO. In determining the densities, the electron impact ionization cross section for $\mathrm{NO}$ at $75 \mathrm{eV}$ was assumed to be $80 \%$ of that for $\mathrm{N}_{2}$. Recent measurements of the $\mathrm{N}_{2}$ and NO electron-impact ionization cross sections by Straub et al. [1996] and by Lindsay et al. [2000], respectively, show that the cross sections for production of the ions $\mathrm{N}_{2}^{+}$and $\mathrm{NO}^{+}$from their parent neutrals are actually comparable. The reported values for the cross sections for production of $\mathrm{N}_{2}^{+}$and $\mathrm{NO}^{+}$by impact of $75 \mathrm{eV}$ electrons are about $1.90 \times 10^{-16}$ and $1.94 \times 10^{-16} \mathrm{~cm}^{2}$, respectively. Thus there are several reasons to believe that the NO densities reported by Viking may not be accurate.

\section{Discussion}

[53] Unlike the SERF2 Martian model ionospheres constructed by Fox et al. [1995], in which distinct lower peaks appeared near $100-105 \mathrm{~km}$ in the profiles for the electron density and the $\mathrm{O}_{2}^{+}$density, in these enhanced X-ray models, only lower shoulders appear. No obvious minimum between the upper peak and the lower peak is apparent, although the lower shoulder is more prominent at high solar activity than at low. Some of the differences can be ascribed to the use of different models, and some to the use of updated cross sections. One change has been to replace the short wavelength photoionization cross sections with those of Verner and Yakovlev [1995], rather than those from earlier calculations [Weisheit, 1974; Daltabuit and Cox, 1972], or earlier compilations [Kirby et al., 1979]. The O photoionization cross sections from threshold to $1 \AA$ were thoroughly updated in 1998. Other photoionization cross sections have been updated in other wavelength ranges [e.g., Fox and Sung, 2001], but all were updated in the short wavelength range. Finally, the SERF2 solar flux spectra of Tobiska [1991] contained significantly larger fluxes of soft X rays than the Hinteregger spectra.

[54] We find that the predicted $F_{1}$ peaks in the $n_{e}$ profile for the SERF2 models are almost the same as those in our standard models. The enhanced X-ray models exhibit larger $F_{1}$ peaks than do those of the SERF2 models. For example, in the high solar activity models the $F_{1}$ peak increases from $1.6 \times 10^{5}$ to $2 \times 10^{5} \mathrm{~cm}^{-3}$ when the soft $\mathrm{X}$ rays are enhanced, compared to the SERF2 model upper peak density of $1.7 \times 10^{5} \mathrm{~cm}^{-3}$. The latter value and that of our standard high solar activity model value are in substantial agreement with the Mariner 6 radio occultation measurement [Fjeldbo et al., 1970], although Mars was closer to the sun at that time than the average that we have assumed 

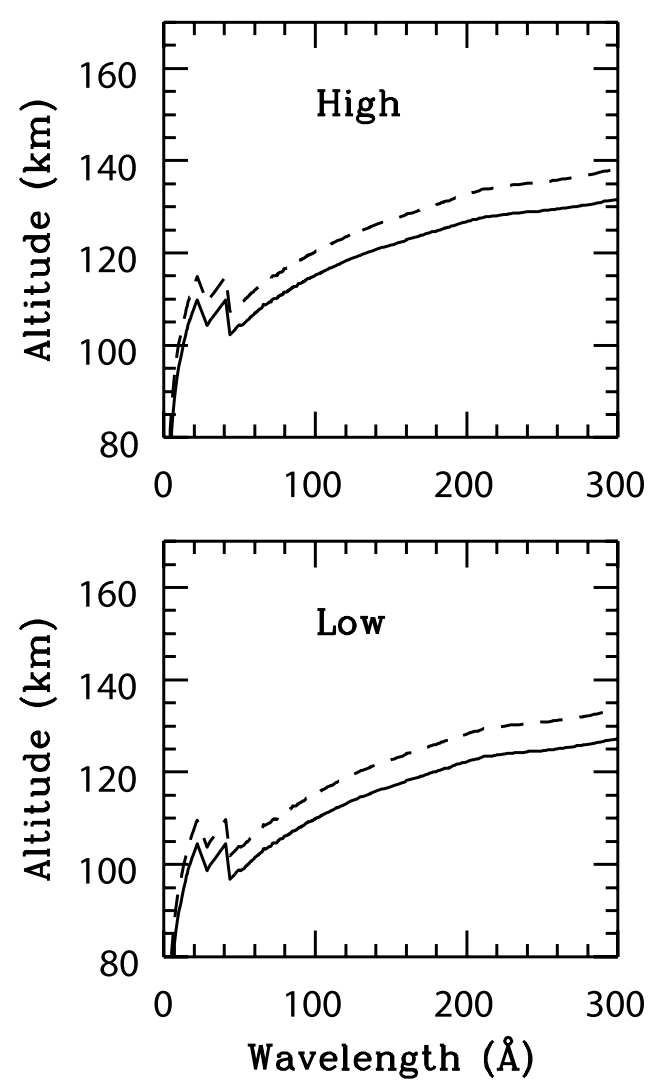

Figure 12. Altitude for which the optical depth is unity for photons with wavelengths of 1 to $300 \AA$. The solid curves are for a solar zenith angle of $0^{\circ}$ and the dashed curves are for a solar zenith angle of $60^{\circ}$. (top) High solar activity standard model ("High"). (bottom) Low solar activity standard model ("Low").

here. For the low solar activity models, the $F_{1}$ peak density increases from $8.7 \times 10^{4}$ to $9.6 \times 10^{4} \mathrm{~cm}^{-3}$ when the soft X-ray fluxes are enhanced, while that of the SERF2 model is about $9 \times 10^{4} \mathrm{~cm}^{-3}$. These comparisons also indicate that our ion production rates near the $F_{1}$ peak may be too large in the enhanced X-ray models.

[55] The E-region $n_{e}$ peak in the low solar activity SERF2 model, about $3 \times 10^{4} \mathrm{~cm}^{-3}$ was between those of the standard and enhanced X-ray models: $2.6 \times 10^{4}$ and $4.4 \times$ $10^{4} \mathrm{~cm}^{-3}$, respectively, but again was closer to that of the standard model. At high solar activity, the lower peak in the electron density profile in the SERF2 model was about 1.1 $\times 10^{5} \mathrm{~cm}^{-3}$, while in our standard and enhanced soft X-ray models the values are $4.9 \times 10^{4}$ and $1.2 \times 10^{5} \mathrm{~cm}^{-3}$. The Mariner 6 flyby occurred during a period of high solar activity. The lower $n_{e}$ peak in the Mariner 6 radio occultation profile is significantly less than that in the SERF2 and enhanced X-ray models, about $7 \times 10^{4} \mathrm{~cm}^{-3}$. Because of the large variability in the soft X-ray fluxes, as exhibited by the MGS RS electron density profiles, we can only conclude that the soft X-ray fluxes at the time of Mariner 6 were midway between those of our standard and enhanced xray models.

[56] We therefore suggest that our computed ion density lower shoulders are not too small to appear as distinct peaks, but the profiles lack a minimum between the upper and lower peaks. The high altitude peaks also are somewhat too large in the current enhanced X-ray models. We conclude that increasing the Hinteregger fluxes by a uniform factor below $200 \AA$ produces too much ionization near and below the main peaks. We can explore this hypothesis further by considering the altitudes where various wavelengths are absorbed.

[57] The region where solar photons deposit most of their energy is near the altitude where optical depth unity occurs. We can identify the wavelength range that is most important in producing the features in the photoionization profile by reference to a plot of the altitude of unit optical depth as a function of wavelength. We present such plots for the "XUV" wavelength region 0 to $300 \AA$ in Figure 12. In Table 5 we present a summary of various wavelength ranges and the altitude region where optical depth unity is reached in our $60^{\circ}$ SZA models. For overhead sun the photons tend to penetrate about $5-7 \mathrm{~km}$ further than for $60^{\circ}$ SZA. Photons with wavelengths in the main part of the EUV (300-910) are absorbed between 133 and $145 \mathrm{~km}$ at low solar activity, and between 138 and $154 \mathrm{~km}$ at high solar activity. The $F_{1}$ peaks are found near the lower end of this altitude range. The $E$ region shoulders occur near 110 and $115 \mathrm{~km}$ for low and high solar activities, respectively. We can see that photons that reach optical depth unity within $5 \mathrm{~km}$ of the E region shoulders are characterized by wave-

Table 5. Altitude Range at Which Optical Depth Unity is Reached and Energy Fluxes in That Range as a Function of Wavelength for Our Standard $60^{\circ}$ SZA Models

\begin{tabular}{|c|c|c|c|c|}
\hline \multirow[b]{2}{*}{$\begin{array}{c}\text { Spectral Range, } \\
\AA\end{array}$} & \multicolumn{2}{|c|}{ Low Solar Activity } & \multicolumn{2}{|c|}{ High Solar Activity } \\
\hline & $\begin{array}{c}\text { Altitude Range, } \\
\text { km }\end{array}$ & 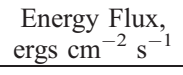 & $\begin{array}{c}\text { Altitude Range, } \\
\text { km }\end{array}$ & $\begin{array}{l}\text { Energy Flux, } \\
\text { ergs } \mathrm{cm}^{-2} \mathrm{~s}^{-1} \\
\end{array}$ \\
\hline $0-14$ & $<100$ & $1.56(-3)^{\mathrm{a}}$ & $<107$ & $3.94(-2)$ \\
\hline $14-55$ & $100-105$ & $2.49(-2)$ & $107-110$ & $1.81(-1)$ \\
\hline $55-75$ & $105-110$ & $4.78(-2)$ & $110-115$ & $1.50(-1)$ \\
\hline $75-100$ & $110-115$ & $4.62(-2)$ & $115-120$ & $1.14(-1)$ \\
\hline $100-130$ & $115-120$ & $1.22(-2)$ & $120-125$ & $2.80(-2)$ \\
\hline $130-150$ & $120-123$ & $9.21(-3)$ & $125-127$ & $2.39(-2)$ \\
\hline $150-200$ & $123-128$ & $2.04(-1)$ & $127-133$ & $5.33(-1)$ \\
\hline $200-250$ & $128-131$ & $8.06(-2)$ & $133-135$ & $3.27(-1)$ \\
\hline $250-300$ & $131-133$ & $8.97(-2)$ & $135-138$ & $5.74(-1)$ \\
\hline $300-910$ & $133-145$ & $1.00(0)$ & $138-154$ & $2.74(0)$ \\
\hline
\end{tabular}

${ }^{\mathrm{a}} \operatorname{Read}$ as $1.56 \times 10^{-3}$ 
lengths in the range of about 50-100 $\AA$. Photons with wavelengths less than about $130 \AA$ reach optical depth unity at low solar activity below $\sim 120 \mathrm{~km}$ and at high solar activity below $\sim 125 \mathrm{~km}$. There are very few solar lines between 130 and $150 \AA$, but the energy flux in this range is not insignificant. In our models, for minima to occur between the $F_{1}$ and $\mathrm{E}$ region peaks, the photon fluxes with wavelengths longward of $130-150 \AA$ need to be reduced. Therefore, increasing the solar fluxes with wavelengths up to $200 \AA$ by a uniform factor cannot produce distinct lower peaks in the profiles.

[58] Solomon et al. [2001] found better agreement with measured terrestrial electron density profiles by increasing the Hinteregger solar fluxes below $250 \AA$ by a uniform factor of 4. Prior model electron density profiles showed a minimum that did not appear in the incoherent scatter data [e.g., Buonsanto et al., 1992, 1995]. Increasing the photon fluxes with wavelengths up to $250 \AA$ increased the overall ionization rate, and in particular that in the region of the spurious "minimum". By contrast, we find that the maximum wavelength of the increased fluxes should be less than $200 \AA$ in order to reproduce those MGS profiles that show a distinct $E$-region peak. Thus while Solomon et al. needed to "fill in" a minimum that did not appear in the measured electron density profiles, we need to "carve out" a minimum in the $n_{e}$ profiles to produce a distinct lower peak. If we were to increase the solar fluxes up to a wavelength of $250 \AA$, the problems with our model would be exacerbated.

\section{Summary and Conclusions}

[59] We have compared models of the Martian thermosphere/ionosphere for the standard and enhanced soft X-ray models. Our standard models were computed with the SC\#21REFW and F79050 fluxes of Hinteregger, and the enhanced X-ray models were constructed by increasing the standard photon fluxes for wavelengths less than $200 \AA$ by factors of 3 and 6 at low and high solar activities, respectively. We find increases at both the upper peaks and lower shoulders of the the ion densities for our enhanced X-ray models. The low altitude "shoulder" in the electron density profile increases by about the square root of the factor by which the solar photon fluxes below $200 \AA$ are assumed to increase. The main $F_{1}$ peak is larger by $\sim 10-$ $25 \%$, and the $\mathrm{O}^{+}$peak increases by about $16-30 \%$. The lower shoulders in the ion density profiles, other than the major ion $\mathrm{O}_{2}^{+}$, increase by about the same factors as the soft $\mathrm{X}$ rays are assumed to increase. In the present models, the shoulders in the $n_{e}$ density profiles in the E-region do not appear as distinct peaks, as do many of the electron density profiles measured by the MGS Radio Science Experiment (D. P. Hinson and the MGS Radio Science Team, Public access to MGS RS standard electron density profiles, available at http://nova.stanford.edu/projects/mgs/edspublic.html, 2003), and the SERF2 models [Fox et al., 1995]. We suggest that the solar fluxes below $200 \AA$ should not be increased by a constant factor, that the upper boundary of the increased fluxes should be $\sim 150 \AA$ or less, or that the fluxes should be increased by larger factors at shorter wavelengths. In general, increasing the solar soft X-ray fluxes up to $200 \AA$ can account for the magnitude of the lower peak seen in the electron density profiles mea- sured by MGS, but not the minimum that is often observed between the $F_{1}$ and $E$-region peaks.

[60] We also find that the densities of $\mathrm{CO}_{2}^{+}$are significant at the lower shoulder, and are linearly proportional to the increase in the soft $X$ rays. Therefore, if measurements of $\mathrm{CO}_{2}^{+}$were available in the lower thermosphere, the increases in the soft X-ray fluxes could be monitored. In situ measurements in this high neutral density region are only possible with a lander; orbiters generally do not dive into such high density regions, except during aerobraking exercises. Remote sensing of this region by a UV spectrometer on an orbiting spacecraft is not possible. The two features of $\mathrm{CO}_{2}^{+}$ in the ultraviolet are the Fox-Duffendack-Barker $\left(A^{2} \Pi_{u} \rightarrow\right.$ $\left.X^{2} \Pi_{g}\right)$ bands and the ultraviolet doublet $\left(B^{2} \Sigma_{u}^{+} \rightarrow X^{2} \Pi_{g}\right)$, very little of either arise from fluorescent scattering of $\mathrm{CO}_{2}^{+}$, and the peaks of these band systems appear near $140 \mathrm{~km}$. It is not known whether the infrared features of ground state $\mathrm{CO}_{2}^{+}$are detectable and sensitive to the $\mathrm{CO}_{2}^{+}$densities of the lower thermospheric region.

[61] The densities of $\mathrm{C}$ and NO show little effect of the enhanced $\mathrm{X}$ rays, but the peaks in the $\mathrm{N}$ density profiles are larger by 23 and $65 \%$ at low and high solar activities, respectively. Increasing the solar soft X-ray fluxes up to 200 $\AA$ cannot account for the large NO densities observed by Vikings 1 and 2 [Nier and McElroy, 1976]. It is possible that the large NO densities measured by the Viking mass spectrometers are an instrumental effect.

[62] We are in the process of constructing models using updated solar spectra. Recent computations using the Solar 2000 v 1.24 a spectra of K. Tobiska (private communication, 2003), which are based on the SNOE soft X-ray data, are similar to those we have presented here [Fox, 2003b]. Further updates of the Solar 2000 model that are based on the measurements of the TIMED SEE instrument [e.g., Woods et al., 2000] will be used in future models when they become available.

[63] Acknowledgments. This work has been supported in part by grant AST0315153 from the National Science Foundation and grants MAG5-13313 and NAG5-12755 from the National Aeronautics and Space Administration.

[64] Arthur Richmond thanks Stephen W. Bougher and another reviewer for their assistance in evaluating this paper.

\section{References}

Acton, L. W., D. C. Weston, and M. E. Bruner (1999), Deriving solar X-ray irradiance from Yohkoh observations, J. Geophys. Res., 104, 14,82714,832 .

Anderson, D. E., and C. W. Hord (1971), Mariner 6 and 7 ultraviolet spectrometer experiment: Analysis of hydrogen Lyman alpha, J. Geophys. Res., 76, 6666-6673.

Ayres, T. (1997), Evolution of the solar ionizing flux, J. Geophys. Res., 102, $1641-1651$.

Bailey, S. M., T. N. Woods, C. A. Barth, and S. C. Solomon (1999a), Measurements of the solar soft X-ray irradiance from the Student Nitric Oxide Explorer, Geophys. Res. Lett., 26, 1255-1258.

Bailey, S. M., T. N. Woods, L. R. Canfield, R. Korde, C. A. Barth, S. C. Solomon, and J. G. Rottman (1999b), Sounding rocket measurements of the solar soft X-ray irradiance, Sol. Phys., 186, 243-257.

Bailey, S. M., T. N. Woods, C. A. Barth, S. C. Solomon, L. R. Canfield, and R. Korde (2000), Measurements of the solar soft X-ray irradiance by the Student Nitric Oxide Explorer: First analysis and underflight calibrations, J. Geophys. Res., 105, 27,179-27,193.

Baluja, K. L., and C. J. Zeippen (1988), M1 and E1 transition probabilities for state within the $2 \mathrm{p}^{4}$ configurations of the $\mathrm{O} \mathrm{I}$ isoelectronic sequence, J. Phys. B, 21, 1455-1471.

Banks, P. M., and G. Kockarts (1977), Aeronomy, vol. A, pp. 144-146, Academic, San Diego, Calif. 
Barth, C. A. (1996), Reference models for thermospheric nitric oxide, 1994, Adv. Space Res., 18(9/10), 179-208.

Barth, C. A., W. K. Tobiska, D. E. Siskind, and D. D. Cleary (1988), Solarterrestrial coupling: Low latitude thermospheric nitric oxide, Geophys. Res. Lett., 15, 92-94.

Barth, C. A., S. C. Bailey, and S. C. Solomon (1999), Solar-terrestrial coupling: Solar soft $\mathrm{X}$ rays and thermospheric nitric oxide, Geophys Res. Lett., 26, 1251-1254.

Barth, C. A., K. D. Manikoff, S. M. Bailey, and S. C. Solomon (2003), Global observations of nitric oxide in the thermosphere, J. Geophys. Res. 108(A1), 1027, doi:10.1029/2002JA009458.

Bauer, S. J. (1973), Physics of Planetary Ionospheres, 223 pp., SpringerVerlag, New York.

Bougher, S. W., R. G. Roble, E. C. Ridley, and R. E. Dickinson (1990), The Mars thermosphere: 2. General circulation with coupled dynamics and composition, J. Geophys. Res., 95, 14,811-14,827.

Bougher, S. W., S. Engel, R. G. Roble, and B. Foster (1999), Comparative terrestrial planet thermospheres: 2 . Solar cycle variation of global structure and winds at equinox, J. Geophys. Res., 104, 16,591-16,611.

Bougher, S. W., S. Engel, R. G. Roble, and B. Foster (2000), Comparative terrestrial planet thermospheres: 3 . Solar cycle variation of global structure and winds at solstices, J. Geophys. Res., 105, 17,669-17,692.

Bougher, S. W., S. Engel, D. P. Hinson, and J. M. Forbes (2001), Mars Global Surveyor Radio Science electron density profiles: Neutral atmosphere implications, Geophys. Res. Lett., 28, 3091-3094.

Brown, R., and C. A. Winkler (1970), The chemical behaviour of active nitrogen, Angew. Chem., 9, 181-254.

Buonsanto, M. J., S. C. Solomon, and W. K. Tobiska (1992), Comparison of measured and modeled solar EUV flux and its effect on the $E-F$ region of the ionosphere, J. Geophys. Res., 97, 10,513-10,524.

Buonsanto, M. J., P. G. Richards, W. K. Tobiska, S. C. Solomon, Y.-K Tung, and J. Fennelly (1995), Ionospheric electron densities calculated using different EUV flux models, and cross sections: Comparison with radar data, J. Geophys. Res., 100, 14,569-14,580.

Butler, K., and C. J. Zeippen (1984), NI forbidden lines revisited, Astron Astrophys., 141, 274-278.

Chapman, S. (1931), The absorption and dissociative or ionizing effects of monochromatic radiation in an atmosphere of a rotating earth, Proc. Phys. Soc. London, 43, 26-45.

Chen, R. H., T. E. Cravens, and A. F. Nagy (1978), The Martian ionosphere in light of the Viking observations, J. Geophys. Res., 83, 3871-3876.

Cleary, D. D. (1986), Daytime high-latitude rocket observations of the $\gamma, \delta$, and $\epsilon$ bands, J. Geophys. Res., 91, 11,337-11,344.

Conway, R. R. (1984), Comments of the interpretation of $3371 \AA$ filterphotometer observations and its implications for the AE-E photoelectron fluxes, Planet. Space Sci., 31, 1223-1228.

Dalgarno, A., and J. L. Fox (1994), Ion chemistry in atmospheric and astrophysical plasmas, in Unimolecular and Bimolecular Reaction Dy namics, edited by C. Y. Ng, T. Baer, and I. Powis, pp. 1-85, John Wiley, Hoboken, N. J.

Daltabuit, E., and D. P. Cox (1972), K-shell photoionization cross sections, Astrophys. J., 177, 855-859.

DeMore, W. B., S. P. Sander, D. M. Golden, R. F. Hampson, M. J. Kurylo, C. J. Howard, A. R. Ravishankara, C. E. Kolb, and M. J. Molina (1992), Chemical kinetics and photochemical data for use in stratospheric modeling, evaluation number 10, JPL Publ., 92-20, 240 pp.

DeMore, W. B., S. P. Sander, D. M. Golden, R. F. Hampson, M. J. Kurylo, C. J. Howard, A. R. Ravishankara, C. E. Kolb, and M. J. Molina (1994), Chemical kinetics and photochemical data for use in stratospheric modeling, evaluation number 11, JPL Publ., 94-26, 284 pp.

Duff, J. W., and R. D. Sharma (1997), Quasiclassical trajectory study of the $\mathrm{N}\left({ }^{4} S\right)+\mathrm{NO}\left(X^{1} \Sigma\right) \rightarrow \mathrm{N}_{2}\left(X^{1} \Sigma_{g}^{+}\right)+\mathrm{O}\left({ }^{3} P\right)$ reaction cross section on the excited ${ }^{3} \mathrm{~A}^{\prime}$ NNO surface, Chem. Phys. Lett., 265, 404-409.

Ferguson, E. E. (1973), Rate constants of the thermal energy binary ionmolecule reactions of aeronomic interest, At. Data Nucl. Data Tables, 12, $159-178$.

Fjeldbo, G., A. Kliore, and B. Seidel (1970), The Mariner 1969 occultation measurements of the upper atmosphere of Mars, Radio Sci., 5, 381.

Fox, J. L. (1992), Airglow and aurora in the atmospheres of Venus and Mars, in Venus and Mars: Atmospheres, Ionospheres, and Solar Wind Interaction, Geophys. Monogr. Ser., vol. 66, edited by J. G. Luhmann, M. Tatrallyay, and R. Pepin, pp. 191-222, AGU, Washington, D. C

Fox, J. L. (1993), The production and escape of nitrogen atoms on Mars, J. Geophys. Res., 98, 3297-3310.

Fox, J. L. (1994), Rate coefficient for the reaction N + NO, J. Geophys. Res., 99, 6273-6276. (Corrigendum, J. Geophys. Res., 101, 7987, 1996.)

Fox, J. L. (1997), Upper limits to the outflow of ions at Mars: Implications for atmospheric evolution, Geophys. Res. Lett., 24, 2901-2904.

Fox, J. L. (2001), The effect of enhanced hydrogen on the nonthermal escape of atoms, Eos Trans. $A G U, 82(20)$, Spring Meet. Suppl., S249.
Fox, J. L. (2003a), The effect of $\mathrm{H}_{2}$ on the Martian ionosphere: Implications for atmospheric evolution, J. Geophys. Res., 108(A6), 1223, doi:10.1029/ 2001JA000203

Fox, J. L. (2003b), The effects of enhanced fluxes of soft X rays on the ionospheres and thermospheres of Venus and Mars, Eos Trans. AGU, 84(46), Fall Meet. Suppl., Abstract A12A-70.

Fox, J. L., and F. B. Bakalian (2001), Photochemical escape of atomic carbon from Mars, J. Geophys. Res., 106, 28,785-28,791.

Fox, J. L., and A. Dalgarno (1979), Ionization, luminosity, and heating of the upper atmosphere of Mars, J. Geophys. Res., 84, 7315-7333.

Fox, J. L., and A. Hać (1997), The spectrum of hot O at the exobases of the terrestrial planets, J. Geophys. Res., 102, 24,005-24,011

Fox, J. L., and K. Y. Sung (2001), Solar activity variations in the Venus ionosphere/thermosphere, J. Geophys. Res., 106, 21,305-21,335.

Fox, J. L., P. Zhou, and S. W. Bougher (1995), The thermosphere/ionosphere of Mars at high and low solar activities, Adv. Space Res., 17(11), $203-218$

Gamallo, P., M. González, and R. Sayós (2003), Ab initio study of the two lowest triplet potential energy surfaces involved in the $\mathrm{N}\left({ }^{4} S\right)+\mathrm{NO}\left(X^{2} \Pi\right)$ reaction, J. Chem. Phys., 118, 10,602-10,610.

Gauyacq, D., C. Larcher, and J. Rostas (1979), The emission spectrum of the $\mathrm{CO}_{2}^{+}$ion: Rovibronic analysis of the $A^{2} \Pi_{u} \rightarrow X^{2} \Pi_{g}$ band system, Can. J. Phys., 57, 1634-1649.

Gérard, J.-C., and C. A. Barth (1977), High-latitude nitric oxide in the lower thermosphere, J. Geophys. Res., 82, 674.

Gérard, J.-C., R. G. Roble, D. W. Rusch, and A. I. Stewart (1984), The global distribution of thermospheric odd nitrogen for solstice conditions during solar cycle maximum, J. Geophys. Res., 89, 1725-1738.

Hanson, W. B., S. Sanatani, and D. R. Zuccaro (1977), The Martian ionosphere as observed by the Viking retarding potential analyzers, J. Geophys. Res., 82, 4351-4367.

Heroux, L., and J. E. Higgens (1977), Summary of full disk solar fluxes between 250 and 1940 A, J. Geophys. Res., 82, 3307.

Heroux, L., and H. E. Hinteregger (1978), Aeronomical reference spectrum for solar UV below A, J. Geophys. Res., 83, 5305-5308.

Herron, J. T., and R. E. Huie (1968), On the reaction of atomic nitrogen with carbon dioxide, J. Phys. Chem., 72, 2235.

Hinteregger, H. E., K. Fukui, and B. R. Gibson (1981), Observational, reference, and model data on solar EUV, from measurements on AE-E, Geophys. Res. Lett., 8, 1147-1150.

Jin, H., T. Mukai, T. Tanaka, and K. Maezawa (2001), Oxygen ions escaping from the dayside Martian upper atmosphere, Adv. Space Res., 27(11), $1825-1830$

Kallio, E., H. Koskinen, S. Barabash, C. M. C. Nairn, and K. Schwingenschuh (1995), Oxygen outflow in the Martian magnetotail, Geophys. Res. Lett., 22, 2449-2452.

Kella, D., L. Vejby-Christensen, P. J. Johnson, H. B. Pedersen, and L. H. Andersen (1997), The source of green light emission determined from a heavy-ion storage ring experiment, Science, 276, 1530-1533.

Kirby, K., E. R. Constantinides, S. Babeu, M. Oppenheimer, and G. A. Victor (1979), Photoionization and photoabsorption cross sections of He, $\mathrm{O}, \mathrm{N}_{2}$, and $\mathrm{O}_{2}$ for aeronomical calculations, At. Data Nucl. Data Tables, $23,63-78$.

Kopp, J. P., D. W. Rusch, R. G. Roble, G. A. Victor, and P. B. Hayes (1977), Photoemission in the second positive system of molecular nitrogen in the Earth's airglow, J. Geophys. Res., 82, 555.

Krasnopolsky, V. A. (1993), Photochemistry of the Martian atmosphere (mean conditions), Icarus, 101, 313-332.

Krasnopolsky, V. A. (2002), Mars' upper atmosphere and ionosphere at low, medium, and high solar activities: Implications for evolution of water, J. Geophys. Res., 107(E12), 5128, doi:10.1029/ 2001JE001809.

Krasnopolsky, V. A., and P. D. Feldman (2001), Detection of molecular hydrogen in the atmosphere of Mars, Science, 294, 1914-1917.

Krasnopolsky, V. A., and G. R. Gladstone (1996), Helium on Mars: EUVE and PHOBOS data and implications for Mars' evolution, J. Geophys. Res., 101, 15,765-15,772.

Krasnopolsky, V. A., M. J. Mumma, and G. R. Gladstone (1998), Detection of atomic deuterium in the upper atmosphere of Mars, Science, 280, $1576-1580$

Lee, J. H., J. V. Michael, W. A. Payne, and L. Stief (1978), Absolute rate of the reaction of $\mathrm{N}\left({ }^{4} S\right)$ with NO from $196-400 \mathrm{~K}$ with DF-RF and FP-RF techniques, J. Chem. Phys., 69, 3069-3076.

Lee, J. S., J. P. Doering, T. A. Potemra, and L. H. Brace (1980), Measurements of the ambient photoelectron spectrum from Atmosphere Explorer: I. AE-E measurements below $300 \mathrm{~km}$ during solar minimum conditions, Planet. Space Sci., 28, 947-971.

Lichtenegger, H., and E. Dubinin (1998), Magnetotail calculations of the planetary ion distribution in the Martian tail, Earth Planets Space, 50, $445-452$ 
Lindsay, B. G., M. A. Mangan, H. C. Straub, and R. F. Stebbings (2000), Absolute partial cross sections for electron-impact ionization of $\mathrm{NO}$ and $\mathrm{NO}_{2}$ from threshold to $1000 \mathrm{eV}, J$. Chem. Phys., 112, 9404-9410.

Liu, Y., A. F. Nagy, T. I. Gombosi, D. L. DeZeeuw, and K. G. Powell (2001), The solar wind interaction with Mars: Results of three-dimensional three-species MHD Studies, Adv. Space. Res., 27(11), 18371846.

Lundin, R., A. Zhakarov, R. Pellinen, H. Borg, B. Hultquist, N. Pissarenko, E. Dubinen, S. Barabash, I. Liede, and H. Koskinen (1989), First measurements of the ionospheric plasma escape from Mars, Nature, 341, $609-612$

Lundin, R., A. Zhakarov, R. Pellinen, S. W. Barabash, H. Borg, E. Dubinen, B. Hultquist, H. Koskinen, I. Liede, and N. Pissarenko (1990), ASPERA PHOBOS measurements of the ion outflow from the Martian ionosphere, Geophys. Res. Lett., 17, 873-876.

Ma, Y., A. F. Nagy, K. C. Hansen, D. L. DeZeeuw, and K. G. Powell (2002), Three-dimensional multispecies MHD studies of the solar wind interaction with Mars in the presence of crustal fields, J. Geophys. Res., 107(A10), 1282, doi:10.1029/2002JA009293.

Ma, Y., A. F. Nagy, I. V. Sokolov, and K. C. Hansen (2004), Three-dimensional, multispecies, high spatial resolution MHD studies of the solar wind interaction with Mars, J. Geophys. Res., 109, A07211, doi:10.1029/2003JA010367.

McElroy, M. B., T. Y. Kong, Y. L. Yung, and A. O. Nier (1976), Composition and structure of the Martian atmosphere: Analysis and results from Viking, Science, 194, 1295-1298.

Nier, A. O., and M. B. McElroy (1976), Structure of the neutral upper atmosphere of Mars: Results from Viking 1 and Viking 2, Science, 194, 1298-1300

Nier, A. O., and M. B. McElroy (1977), Composition of structure of Mars' upper atmosphere: Results from the neutral mass spectrometers on Viking 1 and 2, J. Geophys. Res., 82, 4341-4349.

Nier, A. O., W. B. Hanson, A. Seiff, M. B. McElroy, N. W. Spencer, R. J. Duckett, T. C. D. Knight, and W. S. Cook (1976), Composition and structure of the Martian atmosphere: Preliminary results from Viking I, Science, 193, 786-788.

Ogawa, H. S., and D. L. Judge (1986), Absolute solar flux measurement shortward of $575 \AA$, J. Geophys. Res., 91, 7089-7092.

Petrinec, S. M., W. L. Imhof, C. A. Barth, K. D. Mankoff, D. N. Baker, and J. G. Luhmann (2003), Comparison of thermospheric high-latitude nitric oxide observations from PIXIE, J. Geophys. Res., 108(A3), 1123 doi:10.1029/2002JA009451.

Peverall, R., et al. (2001), Dissociative recombination and excitation of $\mathrm{O}_{2}^{+}$ Cross sections, product yields, and implications for studies of atmospheric airglow, J. Chem. Phys., 114, 6679-6689.

Richards, P. G., and D. G. Torr (1984), An investigation of the consistency of the ionospheric measurements of the photoelectron flux and solar EUV flux, J. Geophys. Res., 89, 5625-5635.

Richards, P. G., J. A. Fennelly, and D. G. Torr (1994), EUVAC: A solar EUV flux model for aeronomic calculations, J. Geophys. Res., 99, 89818992.

Sander, S. P., et al. (2003), Chemical kinetics and photochemical data for use in atmospheric studies, evaluation number 14, JPL Publ., 02-25.
Shinagawa, H., and T. E. Cravens (1989), A one-dimensional multispecies magnetohydrodynamic model of the dayside ionosphere of Mars, J. Geophys. Res., 94, 6506-6516.

Shizgal, B., and R. Blackmore (1986), A collisional kinetic theory of a plane parallel evaporating planetary atmosphere, Planet. Space Sci., 34, 279-291

Solomon, S. C., S. M. Bailey, and T. N. Woods (2001), Effect of solar soft $\mathrm{X}$ rays on the lower ionosphere, Geophys. Res. Lett., 28, 2149-2152.

Stewart, A. I. (1972), Mariner 6 and 7 ultraviolet spectrometer experiment: Implications of $\mathrm{CO}_{2}^{+}, \mathrm{CO}$, and $\mathrm{O}$ airglow, J. Geophys. Res., 77, 54-68.

Stewart, A. I. F., R. R. Meier, L. J. Paxton, S. W. Bougher, and C. G. Fesen (1992), Atomic oxygen in the Martian thermosphere, J. Geophys. Res., 97, $91-102$.

Straub, H. C., P. Renault, B. G. Lindsay, K. A. Smith, and R. F. Stebbings (1996), Absolute partial cross sections for electron-impact ionization of $\mathrm{H}_{2}, \mathrm{~N}_{2}$, and $\mathrm{O}_{2}$ from threshold to $1000 \mathrm{eV}$, Phys. Rev. A, 54, 21462153.

Strickland, D. J., J. Bishop, J. S. Evans, T. Majeed, P. M. Shen, R. J. Cox, R. Link, and R. E. Huffman (1999), Atmospheric Ultraviolet Radiance Integrated Code (AURIC): Theory, software, inputs, and selected results, J. Quant. Spectrosc. Radiat. Transfer, 62, 689-742.

Swaminathan, P. K., et al. (1998), Nitric oxide abundance in the mesosphere lower thermosphere region: Roles of solar soft X rays, suprathermal $\mathrm{N}\left({ }^{4} S\right)$ atoms, and vertical transport, J. Geophys. Res., 103(A6), $11,579-11,594$

Tobiska, W. K. (1991), Revised solar extreme ultraviolet flux model, J. Atmos. Terr. Phys., 53, 1005-1018.

Torr, M. R., D. G. Torr, R. A. Ong, and H. E. Hinteregger (1979), Ionization frequencies for major thermospheric constituents as a function of solar cycle 21, Geophys. Res. Lett., 6, 771-774.

Tyler, G. L., et al. (2001), Radio science observations with Mars Global Surveyor: Orbit insertion through one Mars year in mapping orbit, J. Geophys. Res., 106, 23,327-23,348.

Verigin, M. I., et al. (1991), Ions of planetary origin in the Martian magnetosphere (Phobos/TAUS experiment), Planet. Space Sci., 39, $131-137$

Verner, D. A., and D. G. Yakovlev (1995), Analytic fits for partial photoionization cross sections, Astron. Astrophys. Suppl. Ser., 109, 125-133.

Weisheit, J. C. (1974), X-ray ionization cross sections and ionization equilibrium equations modified in Auger transitions, Astrophys. J., 190, $735-$ 740

Wennberg, P. O., J. G. Anderson, and D. K. Weisenstein (1994), Kinetics of reactions of ground state nitrogen atoms $\left({ }^{4} S_{3 / 2}\right)$, J. Geophys. Res., 99, $18,839-18,846$

Woods, T. N., et al. (2000), TIMED Solar EUV Experiment, Phys. Chem. Earth, Part C, Sol. Terr. Planet. Sci., 25, 393-396.

Zeippen, C. J. (1982), Transition probabilities for forbidden lines in the $2 p^{3}$ configuration, Mon. Not. R. Astron. Soc., 198, 111-125.

J. L. Fox, Department of Physics, Wright State University, Dayton, OH 45435, USA. (jane.fox@wright.edu) 